City University of New York (CUNY)

CUNY Academic Works

2-2019

\title{
A Narrative Inquiry of Associate Degree Nursing Students' Stories About Their Experience of Academic Misconduct
}

Bridget Anne Maley

The Graduate Center, City University of New York

\section{How does access to this work benefit you? Let us know!}

More information about this work at: https://academicworks.cuny.edu/gc_etds/3033

Discover additional works at: https://academicworks.cuny.edu

This work is made publicly available by the City University of New York (CUNY).

Contact: AcademicWorks@cuny.edu 
A NARRATIVE INQUIRY OF ASSOCIATE DEGREE NURSING STUDENTS' STORIES ABOUT THEIR EXPERIENCE OF ACADEMIC MISCONDUCT

by

BRIDGET MALEY

A dissertation submitted to the Graduate Faculty in Nursing in partial fulfillment of the requirements for the degree of Doctor of Philosophy, The City University of New York 
(C) 2019

\section{BRIDGET MALEY}

All rights reserved 
Narrative Inquiry of Associate Degree Nursing Students' Stories about their Experience of Academic Misconduct

by

\section{Bridget Maley}

This manuscript has been read and accepted for the Graduate Faculty in Nursing in satisfaction of the dissertation requirement for the degree of Doctor of Philosophy.

Date

Date

Arlene Farren

Chair of Examining Committee

Supervisory Committee:

Keville Frederickson

Barbara Montero

Karen Roush

THE CITY UNIVERSITY OF NEW YORK 


\begin{abstract}
Narrative Inquiry of Associate Degree Nursing Students' Stories about their Experience of Academic Misconduct

by

Bridget Maley
\end{abstract}

Advisor Name: Dr. Arlene Farren

Academic misconduct is a growing national and global concern. There is a paucity of literature on academic misconduct in nursing. Among the research studies that have been conducted, all but one were quantitative. The purpose of this study is to gain a deeper understanding of Associate Degree (AD) nursing students' experiences with academic misconduct during their nursing education. This study utilized the qualitative method of narrative inquiry to address the research question: What are the stories of Associate Degree nursing students with academic misconduct experiences during their nursing education? This sample included five volunteer research participants who were current associate degree nursing students, focusing on their experiences of academic misconduct. Four themes emerged in the analysis: Theme \#1: Rules: Perception of rules unfulfilled, Theme \#2 Fear of failing greater than fear of getting caught, Theme \#3 Solidarity: Treat others as I want to be treated, and Theme \#4:Success or failure: Cheating throughout the program; you may only be cheating yourself. The study gave voice to students' stories of academic misconduct. Participants in the study revealed intimate stories of their experience with academic misconduct. The stories contribute to a deeper understanding of 
AD nursing students' experience with academic misconduct. The study findings have implications education, practice, and research. 


\section{Acknowledgement}

First I want to acknowledge that this has been a long arduous road to completion. I have had a few bumps in the road but I am coming out on the other side. That perseverance and hard work does get rewarded. That being said I am grateful to the many individuals that have guided me and supported me through this process. I would like to thank the members of my dissertation committee for the taking the time out of their busy schedules to help me accomplish this task. I want to thank my family and friends who kept pushing me to continue, and I would like to thank Cohort 7, we knew we were special from the beginning and the love and support that we have provided for each other is evident in the fact that we will all graduate. I must also mention my God Squad my aunts (Sr. Maryann McHugh and Sr. Alice Reichmeider) who have prayed for Cohort 7 since we began the program and prayed for each of us by name when we needed it. I could have never accomplished this without your love and support.

I am particularly grateful to the chairs of the nursing departments that returned my emails, without them I would not have been able to complete this dissertation. I would like to thank my participants who took the time out of their busy AD nursing students' schedule to meet with me for the purpose of sharing their personal stories. I hope you can appreciate their stories and honesty and try to understand their experience.

A thank you to my dissertation committee for their guidance and expertise. A special thanks to my chair, Dr. Arlene Farren who picked up the pieces for me when it was needed and guided me through this process. I would especially like to thank Dr. Keville Frederickson whose unending support and positive reinforcement helped me believe that this dissertation might come to completion. I am forever grateful. Again thank you all for guiding me through this process. 


\section{Dedication}

This study is dedicated to my family. They have suffered along with me on this long winding road of doctoral studies. To my husband Eddie who has edited more papers than I am sure he ever hoped to , and to my children Matthew, Phillip, and Erin I love you all very much. I especially dedicate this dissertation to my granddaughter Winnie Rose who has brought us so much joy; I want her to know that with love and support anything is possible. 


\section{Table of Contents}

\section{CHAPTER I}

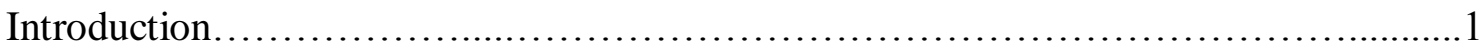

Purpose of the Study and Research Question.......................................................6

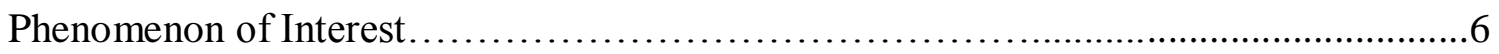

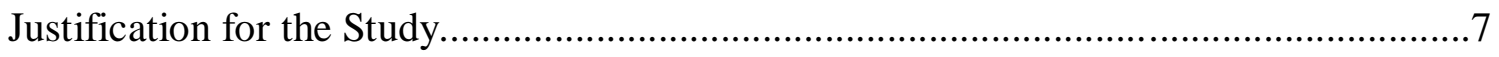

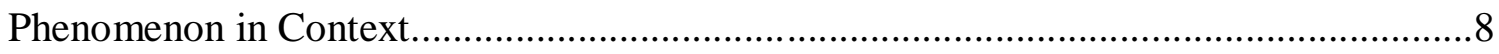

Assumptions and Biases..............................................................

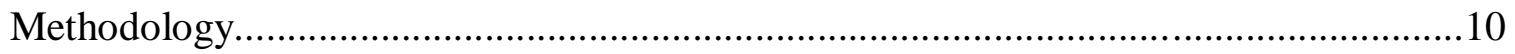

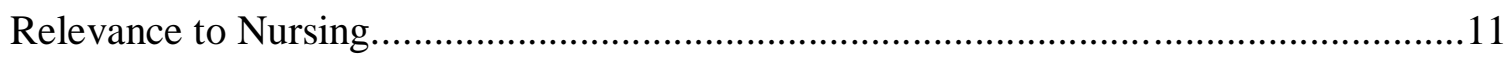

Organization of the Study...................................................... 11

\section{CHAPTER II}

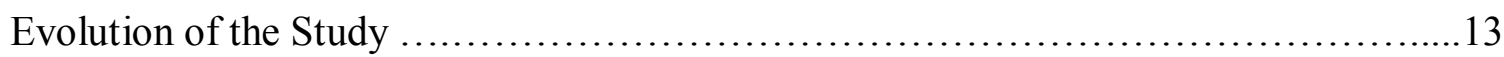

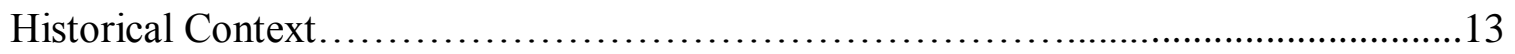

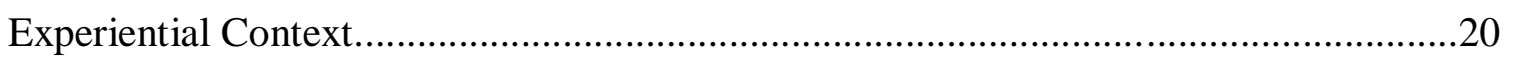

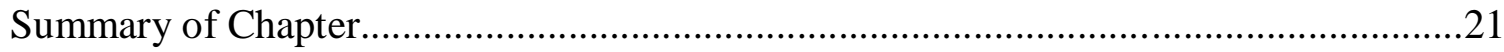

\section{CHAPTER III}

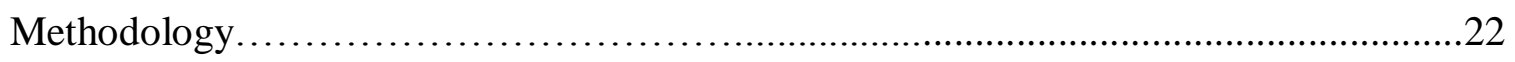

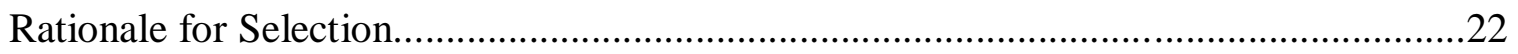

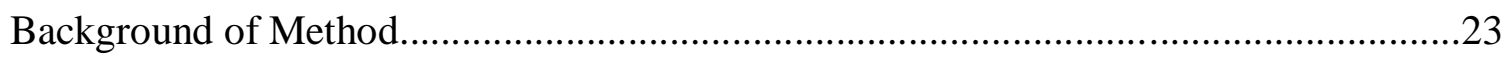

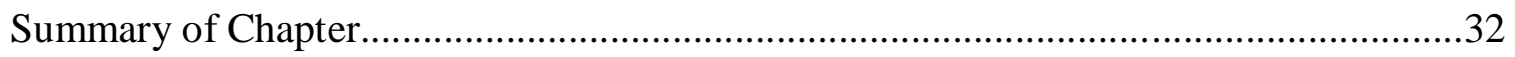




\section{CHAPTER IV}

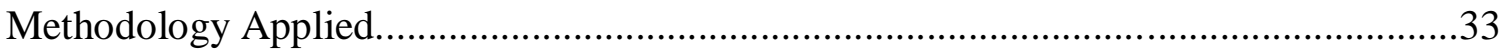

Protection of Human Subjects......................................................

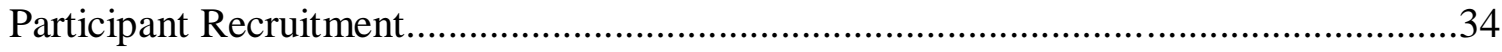

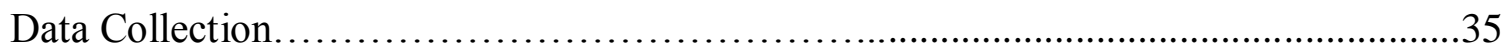

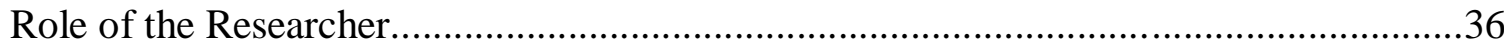

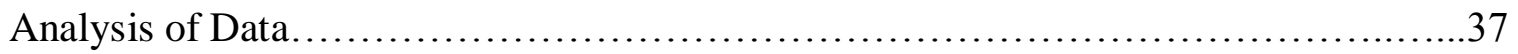

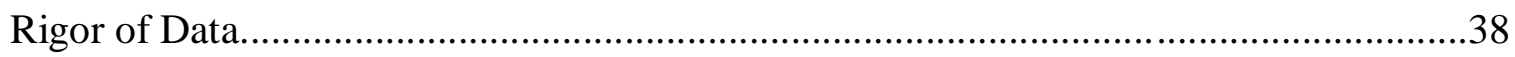

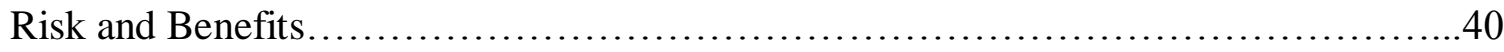

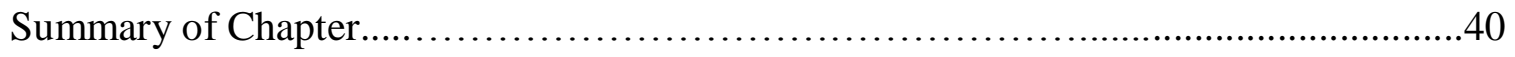

\section{CHAPTER V}

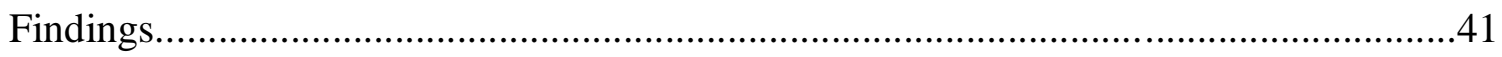

Participants and Procedures....................................................................................

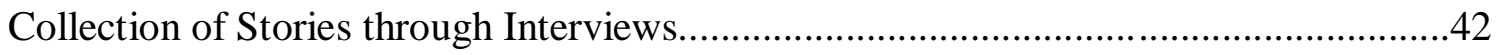

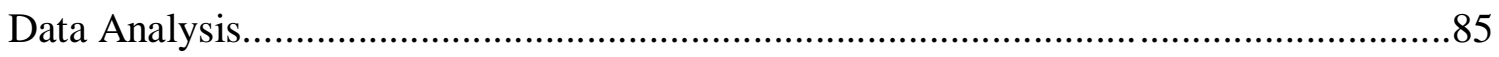

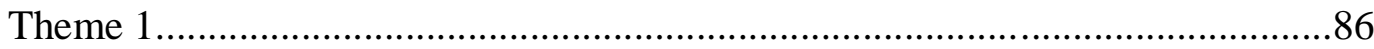

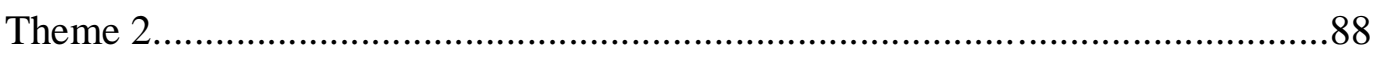

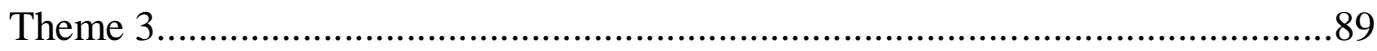

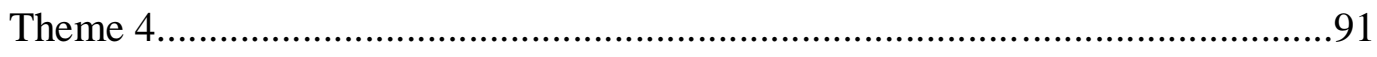

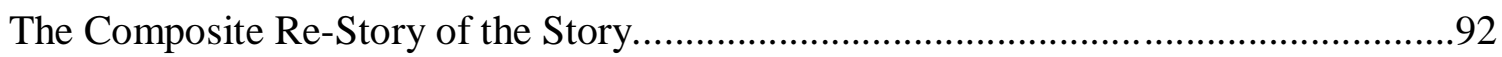

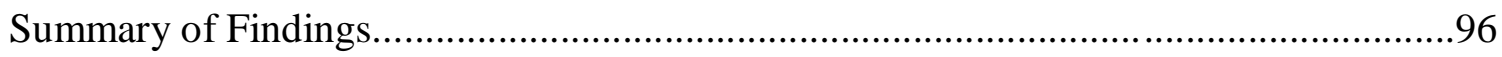

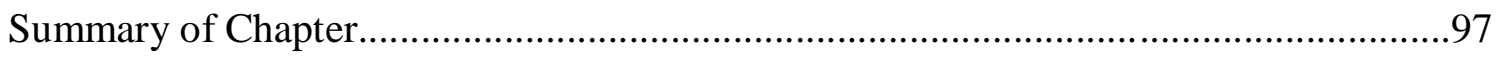




\section{CHAPTER VI}

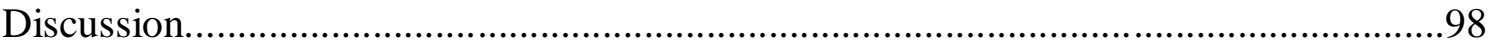

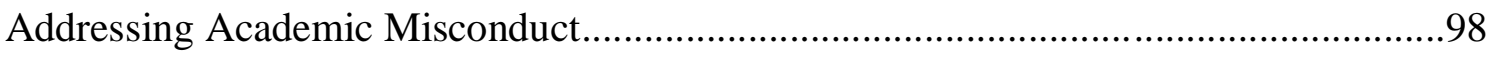

Self Reflection of the Experience of the Researcher.......................................................99

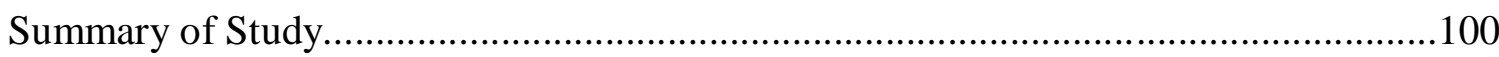

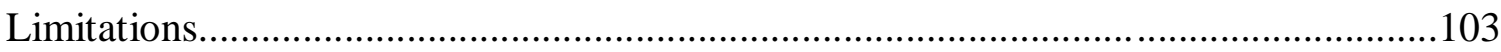

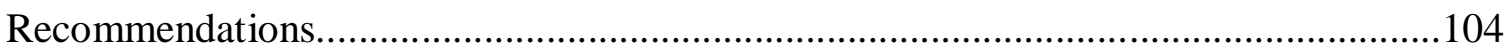

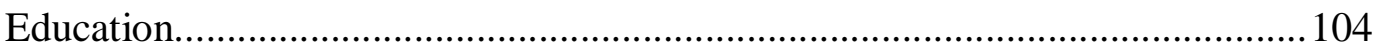

Practice

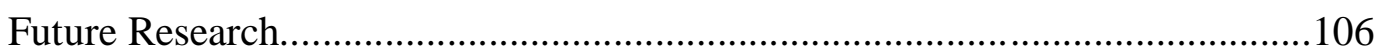

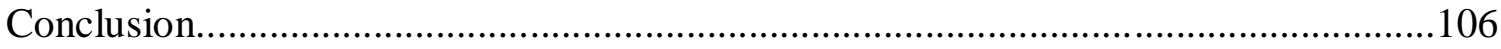

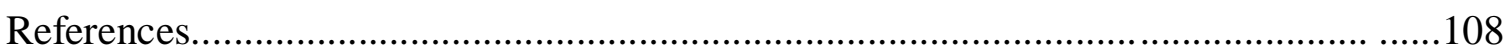

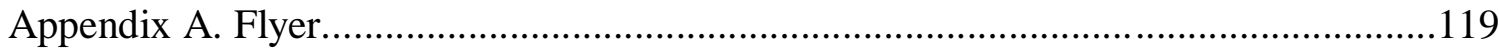

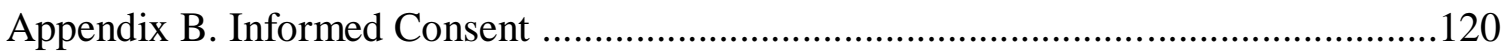

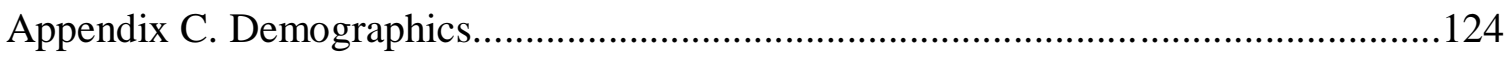

Appendix D. Interview Questions.............................................................................125

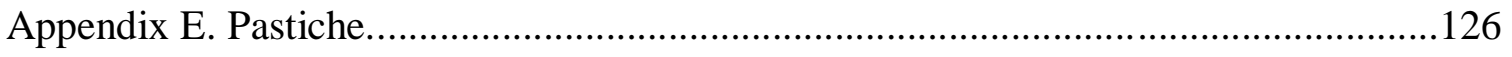




\section{Chapter 1}

Nursing has been identified as the most trusted profession for the past 16 years (Gallup, 2017). The trust that society and patients have given to nurses comes with a responsibility to maintain that trust (de Raeve, 2002). This responsibility is upheld by the integrity and honesty of practicing nurses and is paramount to safe and effective patient care. Nursing students are introduced to these values and the American Nurses Association (ANA) Code of Ethics for Nurses with Interpretive Statements (2015) (referred to as the ANA Code of Ethics) during their education. Although trends in nursing education have changed, 58\% of nursing students are still educated and graduate with an associate degree (AD) (National League for Nursing, [NLN], 2014). Although there has been an increase in nurses who received a bachelor degree, a majority of those nurses initially graduated from an AD program (NLN, 2014). While the concepts of integrity and honesty are part of a nurse's education, the literature suggests that nursing students, like other college students, may participate in academic misconduct (McCabe, 2009). This researcher, using the qualitative method of narrative inquiry, is interested in AD nursing students' stories of academic misconduct. Their experiences of academic misconduct can include participation or witnessing.

Academic misconduct is a global phenomenon affecting almost all countries around the world (Crittenden, Hanna, \& Peterson, 2009; Lin \& Wen, 2007; Naghdipour \& Emeagwali, 2013; Oran, Can, Şenol, \& Hadimli, 2015). Academic misconduct is not a new phenomenon; however, reports of incidences increased gradually from $33 \%$ in 1967 to $67.8 \%$ in 1999; in addition more than $75 \%$ of high-achieving college students are reported to have participated in academic misconduct (International Center of Academic Integrity, [ICAI] 1999, 2013). Studies have shown that students engage in academic misconduct for many different reasons, including 
fear of failure, family pressure, pressure for good grades, and competition (Crittenden et al., 2009; Hilbert, 1987; Lin \& Wen, 2007; Oran et al., 2015). There is evidence that many students in the United States lack understanding of what academic misconduct is, and, because of this, may not realize they are participating in it (Arhin, 2009; McCabe, 2009; Tippitt et al.,2009). Research has indicated that individuals who participate in academic misconduct may have done so throughout a good portion of their education (Bailey, 2001; McCabe, Trevino, \& Butterfield, 2001). The phenomenon is of growing concern to faculty in higher education and educators are challenged to prevent, discourage, and respond to incidents of academic misconduct.

In the United States incidents of academic misconduct seem to be on the rise in professional and educational settings (Crittenden et al., 2009; Lin \& Wen, 2007; Oran et al., 2015). This rise in academic misconduct is of concern. If students see misconduct as normal behavior in the academic setting, they may feel that it is acceptable behavior in the professional setting (Gaberson, 1997; McCrink, 2010). The students' lack of understanding of and insight into academic misconduct (e.g. cheating on exams, giving answers to another student while the exam is in progress, and obtaining answers to exam questions prior to taking an exam) is of great concern (Gaberson, 1997; Krueger, 2014; McCrink, 2010). Academic misconduct is defined as: “intentional participation in deceptive practices regarding one's academic work or work of another" (Gaberson, 1997, p. 14). Prescott (1989) described academic misconduct as "fraudulent behavior involving some form of deception whereby one's work or the work of others is misrepresented" (p 284).

Fraudulent behaviors and practices have significantly increased in recent years in all areas of society (Crittenden et al., 2009). This rise, particularly over the past 20 years, may be the result of increased exposure to incidents by public figures, including behaviors and actions of 
misconduct by business professionals, government officials, and professional athletes. People openly engage in behaviors of misconduct, and these behaviors are publicized by the media. Today's students have grown up in an environment where transgressions by leaders in government, business, and sports are considered common practice (Callahan, 2004; McCabe \& Treviño, 1996). Incidences of academic misconduct are so "pervasive that it is almost commonplace" (Ahrin \& Jones, 2009, p. 710). An example was demonstrated in 2010 when the Columbia University valedictorian used plagiarized material from a comedy routine in the valedictory address (ABC News, 2010). The problem of academic misconduct is of concern to all members of the academic community, especially members of the health professions, where actions may influence patient outcomes.

The possibility that nursing students may engage in academic misconduct is of particular concern to nurse educators who are responsible for educating future professionals (Hilbert, 1988; Vito, 1983). Research has shown that participation in academic misconduct among health professionals may lead to professional misconduct in practice, which for nursing can result in harmful patient outcomes (Bailey, 2001; Gaberson, 1997; Hilbert, 1985; Jeffreys \& Stier, 1995, 2004; La Duke, 2013; McCrink, 2010; Nonis \& Swift, 1998, 2001). This concern led the NLN (2012) to develop Ethical Principles for Nursing Education, to help "foster environments that promote academic and professional integrity", ultimately enhancing patient care and positive outcomes. This document was created to address concerns of nurse educators regarding ethical issues in nursing education including academic misconduct. Because nurses are educated to maintain integrity in all environments, academic misconduct is an especially important topic, to study in nursing education. 
Academic misconduct in nursing education is cause for alarm (Bailey, 2001; Baxter \& Boblin, 2007; Klocko, 2014). Nurses are considered among the most trusted professionals in the country according to Gallup (2017) polls, which measure and track public opinion on political, social, and economic issues. The profession of Registered Nurse was included in the Gallup polls for the first time in 1999 and received this honor each year, with the exception of 2001, when after September 11, firefighters were voted the most trusted profession (Gallup, 2017). Patients trust nurses based on their professional qualifications and education (de Raeve, 2002). Nurses' integrity and honesty are paramount to their practice and for gaining the trust of the patients for whom they provide care (Krueger, 2013). Unethical practices as a student have been correlated with unethical practice behaviors as professional registered nurses (Klainberg et al., 2013). Students who participate in academic misconduct during their education may receive a passing grade for a course but may not have the educational foundation to provide safe care for their patients (Jeffreys \& Stier, 1995,1998, 2004). Nurses who continue with practices of misconduct can place their patients and the facilities that employ them in jeopardy (Gaberson, 1997; Jeffreys \& Stier, 2004).

All nurses and nursing students are expected to uphold an ethical practice based on the ANA Code of Ethics (American Nurses Association, [ANA], 2001, 2015), which is used by nurses, Boards of Nursing, and hospitals to guide practice and address professional integrity, behavior, and misconduct. Nursing students in both associate and baccalaureate programs are introduced to the ANA Code of Ethics during their first nursing course and follow its threads throughout the curricula. In addition, a National Student Nurses' Association (NSNA) (2009) Code of Academic and Clinical Conduct clearly addresses the ethical and moral guidelines and principles that nursing students should uphold during their nursing school education. Provision 
number 6 specifically states that nursing students must actively promote the highest level of moral and ethical principles and accept responsibility for their actions. These values are threaded throughout the curriculum and should be demonstrated by students throughout the nursing education process.

Pre-licensure educational pathways to becoming a registered professional nurse include hospital-based diploma programs, associate degree programs (AD), and generic bachelor degree programs (BS); the latter two are offered through institutions of higher education. All three programs meet the educational requirement for licensure eligibility. Although academic misconduct may be an issue in all programs, the proposed study is focused on AD nursing students because the greatest number (58\%) of pre-licensure programs in the US are AD programs and most US nurses report $\mathrm{AD}$ as the initial degree obtained for their nursing license (National Council of State Boards of Nursing [NCSBN], 2016; NLN, 2014). Although nursing education trends are changing towards a preference for BS-prepared nurses, AD programs continue to be the predominating educational preparation for nurses in the US (NCSBN, 2016; NLN, 2014). For this reason this researcher chose to study AD programs.

Although much research has examined the topic, little progress has been made in reducing academic misconduct. Students have experiences, stories, and perspectives that may better inform our understanding of the problem and point to more effective solutions. Yet, their stories go unheard with little qualitative research exploring the experiences of academic misconduct from the perspective of students. Thus, the purpose of this qualitative study, using a narrative inquiry approach, is to better understand AD nursing students' perspectives of participation in or witnessing academic misconduct during their nursing education. 


\section{Purpose of the Study and Research Question}

The purpose of this study is to gain a deeper understanding of AD nursing students' experiences with academic misconduct, which may include participation in or witnessing academic misconduct during their nursing education process and give voice to their storied experience. This study seeks to address the research question: What are the stories of Associate Degree nursing students with academic misconduct experiences during their nursing education?

\section{Phenomenon of Interest}

The phenomenon of interest is academic misconduct experienced by AD nursing students during their nursing program in an institution of higher learning. Academic misconduct is of concern in all disciplines today, including nursing (McCabe, 2009). Academic misconduct has been defined as "intentional participation in deceptive practices regarding one's academic work or work of another" (Gaberson, 1997, p. 14). Prescott (1989) described academic misconduct as a "fraudulent behavior involving some form of deception whereby one's work or the work of others is misrepresented" (p 284). McCrink (2010) added the idea that behaviors of misconduct include both academic and clinical settings. Behaviors of misconduct in the academic setting are of concern to the nursing profession as research has shown that such behaviors in school may carry over into the clinical setting and be detrimental to the nursing profession and to the patients under a nurse's care (Baxter \& Boblin, 2007; Langone, 2007; Tanner, 2004).

While the subject of academic misconduct has been studied in other disciplines, little research has been conducted in nursing especially among AD nursing students (Kolanko et al., 2006; Tippitt et al., 2009; Woith, Jenkins, \& Kerber, 2012). It is important for nurse educators to be better informed about students' understanding of the experience and perception of academic misconduct so that nursing education can better address this phenomenon. 


\section{Justification for the Study}

Justification for the study is based on the paucity of research that focuses on the nursing students' perspectives of academic misconduct during their education; no studies were found on students' stories of engaging in or witnessing academic misconduct. A qualitative study using narrative inquiry was conducted because the method focuses on "stories lived and told" (Clandinin \& Connelly, 2000, p. 20); this method is used when the researcher tries to understand and make meaning of experience. Narrative inquiry provides a method to give voice to students' stories, which may help this researcher and nursing faculty better understand the phenomenon from the students' perspectives. In the process, a deeper understanding of academic misconduct may lay the foundation for new solutions (Clandinin \& Connelly, 2000).

Although many researchers have examined academic misconduct, not many have focused on the discipline of nursing, and overall most studies have been quantitative and did not seek nursing students' stories on academic misconduct (McCabe, et al., 2001; McCrink, 2010; Nonis $\&$ Swift, 1998). Nurse educators are challenged to educate students to become competent and knowledgeable in order to succeed on the standardized licensure examination and provide safe competent care upon graduation. Academic misconduct may not only impede this outcome (Gaberson, 1997; Jeffreys \& Stier, 2004), but also weaken the trust the public has in the nursing profession and thus undermine the profession of nursing (Kolanko et al, 2006). As Arhin and Jones, (2009) suggest, “understanding student's perception of academic misconduct may be an important first step in curtailing this pervasive problem" (p.711). Researchers addressed the factors that may influence academic misconduct but have not focused on why academic misconduct occurs or which solutions may address the problem (Daniel, Adams, \& Smith, 1994; Klocko, 2014; Krueger, 2013; McCabe, 2009). The use of a qualitative approach to the topic of 
academic misconduct is warranted because the experiences of AD students have not been studied.

\section{Phenomenon in Context}

Academic misconduct is a growing phenomenon among college students in all disciplines (Fontana, 2009; McCabe, 2009; Tipitt et al., 2009). Studies have shown that as many as $40 \%$ to $95 \%$ of college students have reported participating in academic misconduct (ICAI, n.d.;

Langone, 2007) and from $58 \%$ to $94 \%$ of nursing students report participating in or witnessing academic misconduct (McCabe, 2009; Roberts, 1997). The ANA Code of Ethics (ANA, 2001, 2015) represents a guide for ethical nursing practice. This discipline specific document, used throughout nursing curricula, "expresses the fundamental values and boundaries of duty and loyalty the nursing profession has to individual clients and society as a whole" (McCrink, 2010, p. 653). The purpose of higher education is to prepare nursing students for the role of a nurse and prepare them both ethically and academically for professional practice (ANA, 2001, 2015). Participation in academic misconduct undermines the foundation of their education to prepare nursing students for practice and may damage the integrity of the profession (Jeffreys \& Stier, 1998; Kolanko et al., 2007).

Some studies indicate that participation in academic misconduct may transfer to misconduct in the professional setting, which may be detrimental to patients, the organization that employs the nurse, and the profession (Jeffreys \& Stier, 2004; Nonis \& Swift, 2001). This phenomenon is complex and therefore needs to be studied qualitatively to gain possible insight and understanding from the student's perspective, which is unavailable through quantitative studies. In reviewing the literature this researcher found most research on academic misconduct has been done in other disciplines such as business, medicine, and pharmacology. There is a gap 
in the literature exploring the phenomenon of academic misconduct from the student's perspective in the discipline of nursing that needs to be explored. A paucity of literature on academic misconduct in nursing exists and of the research studies that have been conducted, all but one were quantitative. Therefore, the use of a qualitative method such as narrative inquiry will allow this researcher to explore the current knowledge base of students by listening to their stories of academic misconduct during their nursing education. This process will give voice to the students' stories and give the researcher the ability to share that information with nurse educators.

\section{Assumptions and Biases}

Narrative inquiry is a qualitative method that is a collaboration between the researcher and the participants. As a narrative researcher, I believe that the research process allows the researcher and participant the opportunity to begin to develop a trusting relationship that may grow during the process. This trusting relationship will allow students to be truthful about disclosing a dishonest act while talking to me.

As an $\mathrm{AD}$ nursing professor, this researcher has experienced the phenomenon of academic misconduct from some students. Although the foundation of the discipline expects nurses to be honest, academic misconduct exists. My belief is that nursing students should be honest and ethical; and participation in academic misconduct is a destructive force on these ideals. A major area of consideration is the atmosphere of competition to enter and remain in a nursing program. In 2017 nursing schools turned away more than 56,000 qualified applicants (Kavilanz, 2018). As a nursing professor, I have to be aware that when the stakes are high, cheating at some level is always a concern. Because of the nature of the phenomenon being 
researched, it is understandable that nursing students may hesitate to participate in this study and it will be essential to gain the trust of the students who are willing to share their story.

\section{Methodology}

The qualitative method of narrative inquiry is used to give voice to the stories of nursing students' experiences of participation in or witnessing academic misconduct during their associate degree nursing education. Narrative inquiry is a qualitative research method whose data is the collection of stories that may help give meaning to everyday life (Clandinin \& Connelly, 2000; Munhall, 2012). "Narratives reveal, sometimes consciously and unconsciously, the meanings, conventions, dominant beliefs and values of the time and place in which a person lives and develops an identity" (Munhall, 2012, p. 421). Narrative inquiry, because of the intimacy of this research method, may be beneficial to participants, allowing them to gain information about a phenomenon that a quantitative method may not provide. In collaboration with researchers and mentors, this method may help develop nursing knowledge about the phenomenon being studied (Green, 2013). The use of narrative inquiry is meaningful to the present research because developing nursing education science through AD students' stories can facilitate shared learning among educators, researchers, and students regarding academic misconduct. Understanding the meaning, values, and beliefs of AD students through their stories may provide insights that contribute to new solutions (Clandinin \& Connelly, 1998; Lindsay, 2006). Thus to understand fully the AD nursing students' experiences of participating in or witnessing academic misconduct, it is essential to collect and examine their relevant stories.

"Narrative inquiry refers to a method of interpreting texts (e.g., oral, written, visual) to create a common story form (Riessman, 2008) that allows for a way to interpret how people perceive reality, make sense of their words, and perform social actions" (Palese, Petean, \& 
Cerne, 2014, p. 2601). Narrative inquiry can create a new sense of meaning and the significance of a topic by providing an opportunity to listen to and learn from participants in a study. Narrative inquiry can provide a deeper understanding of the context and intricacy of an experience (Clandinin \& Connelly, 2000; Kirkpatrick \& Byrne, 2009). Thus, narrative inquiry was considered the most appropriate method for the present study.

\section{Relevance to Nursing}

This study is relevant to nursing education as academic misconduct has far-reaching implications for patient outcomes and patient safety. Listening to students' stories of their experiences of academic misconduct may help this researcher gain some understanding of the student's perspective of academic misconduct and give voice to that experience. Some researchers have shown that students who participate in academic misconduct may also engage in dishonest practices in the workplace, which could directly affect patient outcomes (Gaberson, 1997; Krueger, 2013; Langone, 2007). This would, in turn, be detrimental to the nursing profession and the organization that employs the nurse, given that patient outcomes rely on a nurse's integrity and good intentions (Jeffreys \& Stier, 2004). Thus, this study is relevant to the field of nursing because it has the potential to inform this researcher and other nurse educators about students' experiences with academic misconduct and provide a deeper understanding of the phenomenon.

\section{Organization of the Study}

Chapter 1 outlined the framework for this study in which associate degree nursing students relate their stories of the experiences with and perceptions of participating in or witnessing academic misconduct during their nursing education. The chapter also described the qualitative method of narrative inquiry that is used to understand the experiences and perceptions 
of the participants. In addition, the chapter presented the aim and relevance of the study; and its research question. Chapter 2 presents evolution of the study; through historical, and experiential contexts. Chapter 3 describes the rationale for selecting the qualitative research method of narrative inquiry. Chapter 4 presents the methodology applied and the procedures for collecting and analyzing data. Chapter 5 presents the findings of the study according to research setting, study sample, study findings, participant experiences, thematic analysis, essential themes, rigor, interpretive statement, and thematic model. Chapter 6 presents a reflection on findings, discusses the literature, and applies the thematic reflection to a nursing model. This includes essential themes; synthesizes the data with literature and applies thematic reflection to a nursing model. This final chapter also presents limitations, implications, researcher reflections, and recommendation for further study. 


\section{Chapter 2}

\section{Evolution of the Study}

The purpose of this research study was to gain a deeper understanding of AD nursing students' experiences with academic misconduct, which may include participation in or witnessing academic misconduct during their nursing education process and give voice to their storied experience. Although the literature has described and discussed academic misconduct, only a limited number of research studies have used qualitative research methods and few studies have been conducted with the $\mathrm{AD}$ nursing student population (Wideman, 2011). No studies have tried to make meaning of students' stories through narrative inquiry. This chapter presents a review of the literature on academic misconduct as related to institutions of higher learning and nursing students to provide a context for the research study.

\section{Historical Context of Academic Misconduct}

Academic misconduct is a growing phenomenon in institutions of higher learning (Keçeci et al., 2011; McCabe, 2009; Woith et al., 2012). Today's college students may not understand that participating in academic misconduct is wrong; and their thinking may be related to the competitive nature of today's society, which emphasizes personal success as more important than social values (Balik, Sharon, Kelishek, \& Tabak, 2010; Woith et al., 2012). Thus, it is important to take an historic overview of the literature related to academic misconduct in institutions of higher education in order to see how higher education has been impacted by widespread social misconduct. From this, the discussion will narrow specifically to academic misconduct in nursing education. 


\section{Academic Misconduct}

The earliest studies of academic misconduct from the 1930s and 1940s, were conducted in institutions of higher learning and examined the attitudes of faculty and students. Mathews' (1932) constructed a survey called the Personal Opinion Blank based on an early form of Character Education Inquiry. The survey contained 36 descriptions of situations involving academic honesty, and participants were asked to indicate if they felt an action was justified, unjustified, or doubtful. In a survey of 494 students and 46 faculty members, the results indicated a great difference between the attitudes of faculty and those of students, as well as between men and women. The Personal Opinion Blank also included a question about observing dishonesty. Only $32 \%$ of students indicated they believed reporting the case was justified; among faculty $67 \%$ thought reporting the action was justified. Conclusions from the Personal Opinion Blank were found to be reliable and valid. Mathews questioned whether higher education fosters acceptance of academic dishonesty and concluded the environment of higher education may lead to academic misconduct, making it a difficult problem to conquer.

Parr (1936), building on Mathews' study, examined two aspects of academic misconduct: the frequency of cheating and what may have caused the action of misconduct to occur. Parr believed that "no person is incorruptible in conduct or behavior" (p. 319) and that under certain circumstances everyone is capable of participating in wrong doing. Parr's study was conducted over a 2 year period. The researcher gave 409 college students (an approximately equal number of men and women) a chance to cheat on their exam. Students were given pretests and posttests on vocabulary words at the beginning and end of the semester. The exam was scored secretly by an assistant and the students were also given a chance to correct their own exams. Each changed answer was considered evidence of dishonesty. The results indicated that 98 men (45\%) were 
dishonest compared to 74 women (38\%). These results were similar to those of other studies conducted during this time period. Parr believed that the results of his study indicated that a large portion of college students were likely to participate in dishonest acts in the classroom; pressures to do well and competiveness among students may increase these tendencies.

Competition was also a primary variable in Drake's 1941 study of 126 students in a women's college where an honor system had been in place for 10 years. Drake gave students an exam, and corrected it before returning the papers to the students; the students were then given the opportunity to correct their own papers. Of the 30 students who cheated, none had scored in the top 25\%. According to Drake, these findings indicated that students who cheated were in the lower achieving group and that cheating grew out of the competitive nature of the college system, as higher grades may lead to opportunities not available to students with lower grades. Drake suggested that professors were unable to detect who was cheating, although students were aware of who did so. Drake concluded that although institutions of higher learning were supposed to build character in their students, the atmosphere of competition fostered misconduct, leading to the possibility that such behaviors could carry over into other activities in similar environments outside of school.

A continued increase in academic misconduct was demonstrated in a later large-scale study, which found an even higher rate of academic misconduct. Bowers (1964) conducted a study with a diverse sample of 5,000 students from 99 United States colleges and universities, $75 \%$ of participants were found to engage in some type of academic misconduct. As researchers continued to study the topic of misconduct, they found that cheating and other forms of misconduct continued to increase, with a modest increase in overall cheating and a significant increase in cheating on exams. In their review of literature for their study Jensen, Arnet, 
Feldman and Cauffman (2002) found that the rate of reported cheating in American colleges and universities rose from 23\% to 90\% between 1941 and 1994.

This increase in cheating was significantly captured in a study by McCabe and Treviño (1993), which replicated Bowers' seminal work. They conducted a study of 31 institutions of higher education across the county. Their findings of high rates of academic misconduct led to McCabe creating the International Center for Academic Integrity (ICAI) in 1992 (McCabe \& Treviño, 1993; McCabe, Treviño, Butterfield, 2002). The ICAI is a consortium of more than 200 colleges and universities that work together to maintain a dialogue on the issues of academic misconduct. The ICAI itself conducted a national study on academic integrity that involved 50,000 undergraduate students at more than 60 U.S. colleges (ICAI, 1999, 2013). The extensive findings revealed that $70 \%$ of students admitted to cheating and almost $40 \%$ admitted to Internet plagiarism (up from 10\% in 1999). McCabe, Treviño, and Butterfield (2001) have continued to conduct numerous studies on academic misconduct in the disciplines of engineering, sciences, and business (McCabe, 1997; McCabe, Butterfield ,\& Treviño, 2006). Academic misconduct in nursing education, was not explored until 1985, when Hilbert began to apply the understanding of academic misconduct to its potential relationship with professional practice.

\section{Nursing Students and Academic Misconduct:}

Hilbert (1985) was the first to study the topic of misconduct in nursing students. Her initial study consisted of 101 senior baccalaureate nursing students, ranging in age from 21 to 49 . Hilbert developed a questionnaire that contained 22 unethical behaviors, 11 from the classroom setting and 11 from the clinical setting. The unethical classroom behaviors were obtained from a previously used instrument and based on a review of literature, and the list of clinical behaviors was compiled from a survey of 16 nursing faculty and assumed to have content validity. A $t$-test 
was performed to determine if there were statistically significant differences between classroom and clinical behaviors, and between men and women. The only statistically significant finding was that females engaged in misconduct in the classroom more than males $(p=0.027)$. The results of the study indicated that $10 \%$ of the students had handed in an assignment completed by someone else, and $2 \%$ had taken an exam for another student. There was a statistically significant relationship between classroom dishonesty and unethical behavior in the clinical setting. Some unethical behaviors included: $59 \%$ admitted to taking hospital equipment and more than half admitted to discussing patients inappropriately. Some of the findings from the study were particularly alarming and unexpected: $19 \%$ had recorded medications, treatments, or observations falsely; $7 \%$ had taken hospital medication for personal use; and $4 \%$ had come to the clinical setting under the influence of alcohol or drugs. In contrast to other studies, more females than males participated in misconduct. Hilbert determined there was a significant relationship between classroom dishonesty and dishonesty or unethical behavior in the clinical area.

Two years later, Hilbert (1987) continued her investigation of unethical classroom and clinical behaviors. This study consisted of 210 senior nursing students from four sites in Pennsylvania, California, and Wisconsin. Using the same instrument from her previous study Hilbert found that five classroom behaviors were much higher than in the previous study. These behaviors included: obtaining exam questions from a student who had already taken the exam (up $23.8 \%$ from $9 \%$ ), copying from someone's exam (up $13.1 \%$ ), allowing someone to copy from an exam (up $13.5 \%$ ), copying from a reference without footnoting (up $14.9 \%$ ), and adding a few items to the bibliography (up $12 \%$ ). None of the 22 behaviors showed a decrease. The results were consistent with Hilbert's previous study which indicated a significant positive relationship between classroom and clinical dishonesty. Consistent with Drake (1941), the most 
common reason for participating in academic misconduct in the classroom was pressure to get good grades.

The third study in Hilbert's body of research examined the relationship of the moral development of nursing students and the incidence of self-reported unethical classroom and/or clinical behaviors (Hilbert, 1988). Hilbert used Kohlberg's (1976) theory of moral development as her framework and the Rest Defining Issues Test to survey 63 upper division nursing students. An inverse relationship was found between moral development and unethical clinical behaviors; the same inverse relationship was not found between moral development and classroom behaviors. Students may not see classroom cheating as affecting anyone else while unethical clinical behaviors may have a direct effect on the patient. Thus, Hilbert suggested that students may not recognize how cheating on an exam can also affect others and that those who cheat in school may ultimately not be prepared to care for patients in the clinical setting.

McCabe (2009) an expert in the field of academic dishonesty, conducted one study among nursing students. McCabe conducted a survey of 2,000 baccalaureate and graduate nursing students, the final sample consisted of 1,098 nursing students (902 baccalaureate, 187 graduate students, and 9 students who did not specify their class level). The findings indicated that at least half the students in undergraduate and graduate nursing programs participated in cheating at least once during their education. McCabe concluded that students from all backgrounds and in all fields of study are capable of misconduct when the pressure for academic success is paramount (McCabe, 2009).

Two studies were found to address academic misconduct in AD nursing students (Krueger, 2013; McCrink, 2010). The McCrink (2010) study involved second-year nursing students in two AD programs. Using a Likert scale to generate the frequency in which students 
participated in misconduct, levels ranged from not unethical, slightly unethical, unethical, very unethical, and extremely unethical. A second survey measured attitudes toward behaviors of academic misconduct and frequency of engagement in such behaviors. Participants included 193 students ranging in age from 20 to 56 . The most common acts of misconduct were found to be discussing clients in a public place with nonmedical personnel (35.3\%); working with other students on assignments when not allowed (24.3\%); found obtaining test questions from other students (21.8\%) the third most common form of cheating; and reporting or recording vital signs that were not taken or remembered incorrectly (13\%). Based on the findings of her study, McCrink concluded that associate degree nursing students' participation in academic misconduct was similar to that of baccalaureate nursing students.

Krueger (2013), conducted a quantitative study on $336 \mathrm{AD}$ nursing students from two different colleges in the Midwest, selected for their diverse population. A self-report study was used to collect the data, and an overall response rate of $71 \%$ was obtained, (college A, 86.1\%; 211/245; college B, 67\% 121/179). An ANOVA and Pearson correlation were used to analyze the data. Krueger had finding that more than half the 336 participants reported cheating in the classroom and clinical setting. The results of this study revealed a difference in attitude of frequency in engagement in academic dishonesty related to gender, semester in the program, and ethnicity. Krueger suggested that qualitative research is needed to help understand students' reasons for participating in dishonesty.

The only qualitative study, conducted prior to Krueger's recommendation, was a hermeneutic phenomenological qualitative study of nursing students in a baccalaureate nursing program. Wideman (2011) examined the meaning of academic dishonesty students: recruited through the school's email system; 11 students agreed to participate in the study and were sent a 
short questionnaire asking demographic information. The method of data collection was indepth, semi-structured interviews. The results indicated that academic misconduct is a complicated phenomenon and students had conflicting views of its meaning. Students reported that pressure and high levels of stress may have influenced their decision to participate in misconduct. Similar to other studies, Wideman's study revealed that students do not have a good understanding of academic misconduct and are unaware of their school's policies and their rights as students. This study supported the need for further discussion of the topic by faculty to increase students' knowledge and understanding of academic misconduct.

\section{Experiential Context}

The phenomenon of academic misconduct is something I witnessed during high school, particularly two incidences of academic misconduct that I remember vividly. The first took place during my freshman year when my friend, who sat in front of me in math class, was caught cheating on an exam. The exam was taken from her and she was given a zero; she subsequently failed the course and had to repeat it the following year. I recall how upset she was as I waited with her while she called her mother.

The second experience happened during my junior year in high school. While taking the trigonometry Regents exam, I witnessed another friend cheating, copying answers from one of the smartest students in our class. I failed the exam by 4 points (the only Regents exam I failed) and felt angry and appalled when this student bragged about cheating. Although I failed the exam, I did not report this act to an educator. These experiences have stayed with me all these years. Now, as a faculty member in an AD nursing program and an $\mathrm{RN}$ to $\mathrm{BS}$ completion program, I often think about the pressures our students are under to perform well and how they may be tempted to cheat. 
I am often asked to discuss the phenomenon of academic misconduct and have been actively involved in and concerned about these discussions. Because of the competitiveness of the nursing program and the fact that classroom exams are created to replicate the National Council Licensing Examination (NCLEX), AD students feel pressure to do well on their exams for fear of dismissal from their program. Educators who administer these exams try to factor in safeguards to prevent potential academic misconduct. For example, multiple versions of the exam are created; students are assigned specific seats to avoid sitting near "friends"; students are asked to leave all bags and electronic devices at the front of the room; even labels from water bottles are removed to deter secret notes. In addition, multiple proctors continually walk around the room during the exam to spot any academic misconduct that might occur. Although these practices can be very time-consuming and stressful for faculty, the integrity of the exams must be upheld, for the sake of the profession and the future nurses we are educating. As guardians of the profession, nursing faculty are responsible for creating an atmosphere where students understand that academic misconduct will not be tolerated (La Duke, 2013).

\section{Summary}

This chapter presented an overview of the historical context of academic misconduct in higher education and, specifically, nursing education. The researcher's experiential context has also illuminated her interest of this phenomenon. Using a qualitative method of narrative inquiry (Clandinin \& Connelly, 2000) for this research study, the researcher hopes to shed light on the topic of academic misconduct and bridge the gap in the existing literature by gaining insight into and giving voice to the experiences of $\mathrm{AD}$ nursing students as they tell their stories of academic misconduct during their nursing education. 


\section{Chapter 3}

\section{Methodology}

The purpose of this study using narrative inquiry was to gain a deeper understanding of AD nursing students' stories of their experience of academic misconduct, either through participation in or witnessing academic misconduct during their nursing education. This study addressed the research question: What are the stories of Associate Degree nursing students with academic misconduct experiences during their nursing education? Chapter 1 of this study introduced the phenomenon of academic misconduct, its relevance to nursing, and the research method. The qualitative research method of narrative inquiry is used to gain a deeper understanding of the phenomenon of academic misconduct among AD nursing students. Chapter 2 provided a review of relevant literature related to academic misconduct within a historical and experiential context. This chapter presents an overview of narrative inquiry, the qualitative method selected for this study.

\section{Rationale for Selection}

A review of the nursing literature indicates that while many studies have addressed academic misconduct, the prevalent method used to conduct research is quantitative, consisting of an examination of data obtained through surveys and questionnaires and presented in the aggregate. Qualitative research, on the other hand, focuses on the experiences of participants to gain a deeper understanding of the phenomenon in question. The present study utilizes the qualitative method of narrative inquiry to provide greater insight from students by giving voice to their stories of participating in or witnessing academic misconduct during their nursing education. 
Qualitative research methods allow the researcher to obtain a deeper understanding of the phenomenon in question. Narrative inquiry was chosen for this qualitative study "due to its ability to capture personal experiences that are difficult to describe in facts and figures" (Haydon \& van der Riet, 2014, p. 198). "Narrative inquiry is an approach to the study of human lives conceived as a way of honoring lived experience as a source of important knowledge and understanding" (Clandinin, 2013 , p. 17). Narrative inquiry is about the relationship formed between the researcher and participant; in this study, it was thought that the use of narrative inquiry would allow students to gain meaning out of the experience, capture the emotion of the experience, have the sense that their story has meaning, and begin to understand the phenomenon under study. This method of research is designed to provide insights for both the participant and the researcher into the meaning and implications of the phenomenon of academic misconduct.

\section{Background of Method}

Qualitative research includes methods that focus on the lived experiences; however, understanding lived experiences is limited to phenomenology and narrative inquiry. Although both focus on the person's experience, phenomenology asks about a recollection of events related to the phenomenon; narrative inquiry goes beyond lived experience and is interested in the relationship between the participant and the researcher (Clandinin, 2006), which includes the contextual nature of the interaction. Language from the interviews are used as data to provide a deeper understanding of the participants experience (Cresswell,2013).

Narrative inquiry emerged as a social science research methodology over the last 30 years in the fields of education and healthcare (Connelly \& Clandinin, 1990; Kim, 2016; Metersky \& Schwind, 2015). This qualitative method views experiences through interviews, bringing together the relationship of knowing and being, which can bring people together in a 
research relationship. Narrative inquiry has been defined "as a way of understanding experience. It is collaboration between researcher and participants over time, in a place or a series of places, and in social interaction with milieus" (Clandinin \& Connelly, 2000, p. 20). It is through the close relationship between the researcher and participant that data can be obtained about an individual's experience and where and when such experience may have taken place (Clandinin \& Connelly, 1994; 2000; Clandinin, 2013). Narrative inquiry, which is rooted in interpretive hermeneutics and phenomenology, is an interpretive and relational inquiry for studying experience as story (Clandinin \& Connelly, 2000; Josselson, 2006).

Narrative inquiry rests on the assumption that participants gain understanding of their experience through telling their stories with a beginning, middle, and end (Bell, 2002). By giving participants the opportunity to reflect on life experiences while telling their stories, linking past, present, and future (Haydon \& van der Riet, 2014), it helps individuals understand their lives and make sense of their life events (Sandelowski, 1991). Narrative inquiry affords the researcher an insider view, the ability to gain an understanding of a phenomenon from the perspective of the participant; this then may help further illuminate the phenomenon being studied (Green, 2013).

Narrative inquiry is a way of understanding human experience through stories that, in turn, provide a deeper understanding of human phenomenon and human existence (Kim, 2016), John Dewey's (1938/1997) pragmatic philosophy of experience is the philosophical underpinning of narrative inquiry. The Deweyan view of experience recognizes "the embodiment of the person living in the world, who shapes and is shaped by the social, institutional, and cultural narratives of the person's experiences" (Clandinin \& Rosiek, 2007, p. 13). Dewey's philosophical approach of experience is conceptualized as both personal and 
social, meaning that to be able to understand people, one needs to look at their personal experiences and how they interact with other people (Ollerenshaw \& Creswell, 2002). Dewey held the belief that what one experiences is influenced by previous experiences and therefore leads to future experiences. Clandinin and Connelly (2000) interpret Dewey's ideas as "education, experience, and life are inextricably intertwined" (p. xxiii).

Clandinin and Connelly's narrative inquiry (2000), includes Dewey’s temporal, relational, and contextual qualities, in the development of three commonplaces which they named temporality, sociality, and place. They defined narrative inquiry (Clandinin \& Connelly, 2000) as a way to understand the human experience, and later expanded their definition to include the following: "Narrative inquiry is the study of experience as story, then is first and foremost a way of thinking about experience" (Connelly \& Clandinin, 2006, p. 477).

\section{Three Commonplaces of Narrative Inquiry}

Connelly and Clandinin's (2006) narrative inquiry qualitative research approach is “a personal experience method that explores and interprets the lived and told experience through the three dimensions of experience, referred to as common places: temporality, sociality, and place p. 479)." The narrative inquiry researcher explores the three commonplaces, which are integral with each other, and attend to the four directions (inward, outward, backward, and forward). To undertake a narrative inquiry, a researcher needs to conduct "simultaneous exploration of all three commonplaces" (Connelly \& Clandinin, 2006, p. 479), while simultaneously being aware of the four directions of inward and outward, backwards and forward. The focus on one cannot exclude the others; all three must be included while conducting the research (Clandinin, Pushor, \& Orr, 2007). 


\section{Commonplace One}

Temporality or continuity is central to narrative research; events must be placed in a context of time (Clandinin \& Connelly, 2000). Events and people always have a past, a present, and a future. These events can be told as stories that are often written and rewritten over time.

Once told, the researcher seeks to examine all the stories for analysis and retelling of one unified story based on each participant's story (Clandinin \& Connelly, 2000; Connelly \& Clandinin, 2006). While thinking about this commonplace, the researcher incorporates the four directions of Clandinin and Connolly's narrative inquiry, which incorporate Dewey's notion of interaction, looking inward and outward, backward and forward, between the past, present, and future as the researcher and participant think about their own experiences (backward and forward) from the past which may lead them to their present experiences.

\section{Commonplace Two}

Sociality, the way stories are interpreted, may be influenced by the way individuals interact with one another (relationship) and the way the inquirer (researcher) receives the information (Clandinin \& Connelly, 2000). This commonplace coincides with one of the four directions. This direction is inward, which includes the searching of one's feelings and emotions about the topic of research. The participant and the researcher may experience feelings they have not thought about in some time when talking about the phenomenon being studied. "Narrative inquirers are concerned with personal conditions and, at the same time, with social conditions. By personal conditions we mean the feelings, hopes, desires, aesthetic reactions, and moral dispositions" (Connelly \& Clandinin, 2006, p. 480). Social conditions consist of the environment, surrounding factors, and forces around the individual, which may affect an 
individual's circumstance related to the phenomenon under inquiry (Clandinin \& Connelly, 2000; Connelly \& Clandinin, 2006).

Another dimension of the sociality commonplace is the relationship between participant and inquirer; this aspect is very important in narrative inquiries where there are participants. In such cases, "inquirers are always in an inquiry relationship with participants' lives. We cannot subtract ourselves from relationship" (Connelly \& Clandinin, 2006, p. 480).

As a doctoral student this researcher developed a relationship with potential participants by first meeting them collectively and speaking to them as a group. This action made the researcher human to the participants, not just a flyer hanging on the wall. The researcher became real, someone with a specific purpose and specific need, that is, a need for study participants in order to complete research and dissertation and graduate. Once participants reached out to the researcher, an effort was made to ensure that each felt comfortable, assured that their identity would be kept confidential and that no one from their program would know of their participation. The researcher's calm demeanor during interviews allowed participants to feel comfortable telling their stories. The relationship continued as the researcher read and reread their stories first to create interim data and then achieve a final data collection, an amalgamation of their stories into one chronological story.

\section{Commonplace Three}

Place is "the specific concrete, physical and topical boundaries of place or sequence of places where the inquiry and events take place" (Connelly \& Clandinin, 2006, pp. 480-481). Place includes the physical space where the inquiry or event occurs and incorporates the direction of outward, which refers to the environment or outside influences that both the participant and inquirer may be experiencing (Connelly \& Clandinin, 2000; Clandinin, 2013). 
The important consideration here is "recognizing that all events take place some place" (p. 481), and where the story is spoken can influence its presentation (Clandinin \& Connelly, 2000).

Incorporating the methodology into a method, the inquirer thinks narratively throughout the research process. This helps the researcher fluctuate between the three commonplaces and four directions during the inquiry process (Clandinin, 2013).

\section{Thinking Narratively}

Thinking narratively incorporates understanding of the three commonplaces and four directions; it means understanding the notions of "temporality, people, action, certainty, and context" (Clandinin \& Connelly, 2000, p. 21). Incorporated in the three commonplaces are the concepts of the four directions: looking inward and outward, backward and forward. Inward is necessary to discover the feelings and emotions that the data elicit, while outward examines the environment and social constructs influencing the participant's story. In addition the researcher transitions backward and forward in time to look at changes in emotions within the stories (Clandinin \& Connelly, 2000).

Connelly and Clandinin (2006) proposed seven considerations to follow when thinking narratively; although these are not necessarily unique to narrative inquiry, "they are crucial to it and to the habit of thinking narratively" (p 481).

1. Imagining a lifespace: The narrative inquirer must imagine the phenomenon being studied, the participants, and the place where the phenomenon occurs. Similarly, the researcher must also be able to imagine the participants existing in an ever-changing life space. Connelly and Clandinin added the third commonplace of place to Dewey's dimensions of experience because where the experience takes place can influence the 
experience, making the awareness of place important to the phenomenon of interest (Connelly \& Clandinin, 2006).

2. Living and telling as starting points for collecting field texts: These terms are used for narrative inquiry; the starting point of the inquiry is often the difference between "life as lived in the past (telling) and life as it unfolds (living)" (Connelly \& Clandinin, 2006, p. 482). The researcher interviews participants (telling), and may choose to start with the more difficult and time-consuming aspect of the participant's living (Connelly \& Clandinin, 2006). Although it may be difficult to tell a story, "the more difficult but important task is the retelling of stories that allow for growth and change" (Clandinin \& Connelly, 2000, p. 71). One purpose of narrative inquiry is enhancing personal and social growth (Clandinin \& Connelly, 2000). Through the telling of stories the participant and inquirer may reflect on the lessons they may be learning about themselves and the phenomenon being studied.

3. Defining and balancing the commonplaces: This is an "analytic task; that is the inquirer needs to examine, describe and specify commonplace features to be built into the study" (Connelly \& Clandinin, 2006, p. 482). These concepts may prove challenging for a beginning researcher because it is necessary to "hold an imaginary changing whole in mind while analyzing it into researchable components" (Connelly \& Clandinin, 2006, p 482).

4. Investment of the self in the inquiry: It is important to remain as the researcher during the study. The nature of narrative inquiry and the narrative relationship between participant and researcher challenges the researcher to separate personal feelings and experiences from the study. As part of the research process, intimacy and 
relationship with participants are necessary, but the researcher needs to plan a way to achieve this and identify their participation in the study (Connelly \& Clandinin, 2006). To achieve this intimacy but maintain separate personal feelings and experiences, this inquirer kept a reflexive journal to record feelings and ideas about the phenomenon before and after meeting with participants.

5. Researcher-participant relationship: It is also important to recognize the researcher's relationship with the participant. If the study involves living with a participant, this relationship will be more intimate than if the researcher is simply conducting interviews. In either case, the researcher must be aware of boundaries and separate himself or herself from the data (Connelly \& Clandinin, 2006).

6. Duration of the study: Depending on the type of study - whether living with participants or telling through participant interviews - the researcher must be aware of how much time to devote to the study. Some researchers will devote more time to being in the field with participants to collect data while others will devote more time to interpret data to make meaning from the data (Connelly \& Clandinin, 2006). This inquirer used interviews to obtain data; therefore, more time was devoted to interpreting the data to make meaning from the data.

7. Relationship ethics and narrative inquiry: The inquirer must reflect on one's everyday life as a starting point for thinking about ethical considerations related to the participants. "Ethical considerations permeate narrative inquiries from the start to finish: at the outset as ends in view are imagined, as inquirer-participant relationships unfold, and as participants are re-represented in research texts" (Connelly \& Clandinin, 2006, p. 483). Often the researcher has an ethical dilemma while 
interpreting the text and making judgments based on the data. Spending time with the data to create a re-representation of each participant's experience that represents each person's story may help with this issue (Connelly \& Clandinin, 2006).

Utilizing the steps to thinking narratively, this researcher had the opportunity to think about the phenomenon under study, how to begin the study, and how to define boundaries between the researcher and participant, and uphold the ethics of the relationship in narrative inquiry. Although at times this may seem challenging it is important for the researcher to remember these important steps to the process of thinking narratively.

\section{Justification}

The narrative inquirer must think about justifying the research in three different ways: personal, practical, and social (Clandinin \& Huber, 2010). "For narrative inquirers, it is crucial to be able to articulate a relationship between one's personal interests and sense of significance and larger social concerns expressed in the works and lives of others" (Clandinin \& Connelly, 2000, p 122). The first justification is personal justification: why is this study important to the

researcher? This study is important to me, as researcher, because I am a professor in an associate degree nursing program at a college and a nurse educator who has identified academic misconduct as a critical problem in nursing education. This phenomenon needs to be studied to gain a deeper understanding of the students' experience of academic misconduct narratively.

The second justification is practical justification, which involves the possibility of shifting or changing practices. As a faculty member in an AD program, my responsibility is to continually improve upon nursing education. The use of students' stories, may help uncover some of the reasons why students engage in academic misconduct and help in modifying the 
nursing program. Modifications to the nursing program may lead to the education of more ethical and well-prepared nurses.

Lastly, social justification, addresses the "so what or who-cares questions surrounding research undertakings" (Clandinin \& Huber, 2010, p. 438). Findings from this narrative inquiry may help students self-view as a person of integrity affecting student-student relationships, student-to-teacher relationships, and the transition to professional practice as a nurse graduate. This experience may help future nurses recognize the deleterious consequences of academic misconduct and behaviors of misconduct in their clinical practice.

\section{Summary of Chapter}

In summary, narrative inquiry is a method and technique for understanding a phenomenon through the stories told by participants. This chapter discussed the background of the method and philosophical underpinnings of narrative inquiry and its justification for its selection as a method for the present study. The following chapter presents the process of applying the chosen method. 


\section{Chapter 4}

\section{Methodology Applied}

The purpose of this study using narrative inquiry was to gain a deeper understanding of AD nursing students' stories of their experience of academic misconduct, either through participation in or witnessing academic misconduct during their nursing education. This study addressed the research question: What are the stories of Associate Degree nursing students with academic misconduct experiences during their nursing education? This chapter presents the narrative inquiry method applied to the research process used for this study including protection of human subjects, participant recruitment, data collection procedures, security of data, and analysis of data.

\section{Protection of Human Subjects}

Approval for this study was obtained from the Institutional Review Board (IRB) at the College of Staten Island, City University of New York (CUNY) where the researcher's sponsor is a faculty member. Approval was obtained, and the researcher recruited AD nursing student volunteers to participate in the study. Participants for the study were accepted into a prelicensure AD program and currently taking courses in a nursing curriculum. This researcher did not recruit participants from her own program. Each participant was allowed time to ask questions regarding the informed consent process and written consent forms. The purpose of the study, the procedures to be used, and perceived risks, benefits, and compensation as well as voluntary participation/withdrawal, and confidentiality were discussed with each participant. The signed consent form is kept in a locked cabinet in the researcher's home separate from the code book, demographic questionnaire, audiotapes, and transcripts. 
Once participants agreed to participate in the study a pseudonym was assigned to their demographic questionnaire, audiotapes, and transcripts. According to the IRB guidelines all materials obtained during this study will be shredded and destroyed, including audio recordings 3 years after completion of the study. Participants were informed pseudonyms are used in the document and will be used in any publications that result from this study. Every effort was made to reduce anxiety on the part of participants related to breach of confidentiality. None of the participants expressed feeling any negative consequences by participating in the study.

\section{Participant Recruitment}

The researcher used a purposive method of sampling for this qualitative study. Purposive sample helps recruit participants who will best contribute to the study because they have insider (emic) knowledge of the phenomenon of interest (Polit \& Tatano-Beck, 2017; Silverman, 2006). A flyer was used to make $\mathrm{AD}$ students aware of the study. $\mathrm{AD}$ students enrolled in a particular course were invited to participate, in addition, snowball sampling which is recruitment through word of mouth, was used. There is no required sample size for qualitative research; the focus is on the quality of the information obtained, including the experience, events, and settings. The guiding principle is data saturation (Munhall, 2012). Narrative inquiry is an in-depth study of human experience that usually involves 1-5 participants (Cresswell, 2013; Lindsay, 2006;

Schwind, 2003). Data saturation is the process of the researcher reading and rereading the transcripts for recurring themes until the researcher finds that sampling more data will not lead to more information related to the research question.

Specifically, the researcher interviewed AD nursing students in pre-licensure programs except from her own program, who participated in or witnessed academic misconduct during their nursing education. After IRB approval was obtained, the researcher emailed the chairs of 
the nursing departments to introduce herself and describe the study, and permission to hang flyers (Appendix A) in the nursing department. As this approach did not prove to be fruitful, the researcher asked for permission to speak in person to students in the nursing program. Although still challenging, led to the recruitment of a few participants.

Nursing students who agreed to sign the informed consent (Appendix B) were interviewed in a mutually agreed upon neutral place. The informed consent was explained to each participant, participation in the research study was voluntary, and they could withdraw from the research study at any time. Each participant was asked to complete a demographic sheet (Appendix C) during the consent process. Each interview lasted about an hour.

\section{Data Collection}

The intimate nature of the narrative inquiry process requires the researcher to be conscious of the possible consequences to the participant. Relational ethics guides the research process (Clandinin \& Connelly, 2000). At the interview session, the participants completed a short demographic form and signed the consent form before beginning the interview. The researcher collected data through interviews that began with an open-ended question (Appendix D) asking participants to tell their story about their experience of academic misconduct. Based on prior narrative studies, it was anticipated that each interview would last approximately 60 minutes (Haydon \& van der Riet, 2014; Metersky \& Schwind, 2015). The interviews took place at a mutually agreed upon date and time and in a neutral place. During the interview the researcher listened intently to participants and paraphrased statements back to the participants to ensure understanding (Lindsay \& Schwind, 2016).

This researcher conducted all the interviews, and digitally recorded them. A pseudonym was used for the participants during the interview. Participants were enrolled until no new 
information was obtained, saturation was reached, and the collected interviews proved sufficient to describe the phenomenon of academic misconduct among $\mathrm{AD}$ nursing students. The researcher used a transcriptionist to transcribe the digital recordings. The researcher read and reread the transcripts until saturation was reached, and revisited the literature based on the themes revealed.

\section{Role of the Researcher}

The responsibility of the researcher is to tell the stories of participants as accurately as possible. The researcher in this study recruited potential participants, explained and obtained the consent procedure, conducted all interviews, and hired a transcriptionist to transcribe the recordings. During the interview process the researcher was aware of the intimate relationship between herself and the participants and the tensions that might arise as both entered into the three commonplaces and four directions. The process of narrative inquiry has the potential to enable both the researcher and the participants to gain deeper insight into the phenomenon of academic misconduct.

A literature review on the phenomenon was conducted to provide a rationale for this research study. The researcher continued to review the literature during the analysis process to explore concepts that might emerge from the inquiry conversations (Lindsay \& Schwind, 2016). The transcripts of all data (including digital-recordings and interviews) included assigned pseudonyms to protect the identities of participants and to ensure anonymity. The researcher secured the recordings, flash drives with digital recordings, consent forms, and demographic sheets in a locked file cabinet in her office. These will be destroyed after 3 years. 


\section{Analysis of Data}

The researcher analyzed the data using Clandinin and Connelly's (2000) method of narrative inquiry. The researcher used a reflexive journal before and during the research process to record any thoughts and feelings that might emerge during the research process (Metersky \& Schwind, 2015). This method of analysis requires the researcher to "think narratively and openly within the three dimensional narrative inquiry space of temporality, sociality, \& place" (Law \& Chan, 2015, p. 1841). Using these three domains (temporality, sociality, and place) provides structure to the narrative inquirer's analysis. Within this framework, the four directions of looking inward and outward, backward and forward are used. Inward is necessary to discover the feelings and emotions that the data elicit, while outward examines the environment and social constructs influencing the participant's story. In addition the researcher transitioned backward and forward in time to look at changes in emotions within the stories (Clandinin \& Connelly, 2000). The researcher read and reread all collected data and listened to the audio recordings to search for patterns, threads, and tensions embedded in the participants' stories and the overall social setting. Documents for analysis included the transcripts of the interview and participant checks, researcher's field notes (verbal and non-verbal communication, environment, and situation surrounding interview) and reflexive journal.

The process of narrative inquiry does not end the relationship between participant and researcher; rather the relationship shifts from collecting the data to retelling stories through research texts by the researcher (Clandinin \& Connelly, 2000). During the process of analysis and interpretation, the field texts (which include interview and researcher's field texts) are "woven into the development of research texts" (Clandinin \& Connelly, 2000, p. 119). The researcher remains open to reinterpretation and reconstruction of the data during this process 
(Clandinin \& Connelly, 2000). For this study, the researcher looked at narrative threads along with other data, including the researcher's memos and notes, to ensure that the data collected from participants points towards the same findings. This process of cross examination provided a method of triangulation.

\section{Rigor of the Data}

Rigor in qualitative research is defined differently than rigor in quantitative research because the desired outcome is different. The researcher maintains openness, relevance, methodological congruence, and scrupulous adherence to a philosophical perspective, which leads to good qualitative data that are descriptively accurate and interpretively rich and robust (Burns \& Grove, 2013; Polit \& Tatano-Beck, 2017). "Like other qualitative methods, narrative relies on criteria other than validity, reliability, and generalizability" (Connelly \& Clandinin, 1990, p. 7)

In qualitative research trustworthiness is used to assess the study's rigor (Polit \& TatanoBeck, 2017). Lincoln and Guba's (1985) four criteria (credibility, transferability, dependability, and conformability) and authenticity are used to evaluate trustworthiness. The study was planned and conducted with attention to trustworthiness. Credibility is the truth in the data. Data came from the transcripts and presented verbatim to ensure the participants' stories were exact. Transferability, in this study was associated with female AD nursing students who told a story of witnessing academic misconduct. Dependability refers to the stability of data over time and conditions; it is associated with credibility. Conformability is concerned with the objectivity and neutrality of data, which was addressed in this study by seeking participants' check of their transcripts to ensure their perception of the story was accurately and correctly represented. Authenticity was addressed in a variety of ways, including using reflexive journaling, recordings 
and verbatim transcript, and conducting the research until data saturation was evident. Rigor in the study was addressed through attending to the criteria common to qualitative research (Connelly \& Clandinin, 1990; Lincoln \& Guba, 1985; Munhall, 2012; Polit \& Tatano-Beck, 2017).

Procedural rigor was achieved by following the methodology presented and following the steps to that method. This researcher was sensitive, respectful, and fully present to each participant (Munhall, 2012, p. 438). Ethical rigor was achieved by gaining approval from the IRB before proceeding with the study and obtaining consent from the participants; this included answering any questions and concerns the participants had about the study, ensuring participant confidentiality, and securing all data materials obtained during this study (Munhall 2012).

Auditability in this study was addressed by the researcher to describe in as much detail as possible the purpose of the study, the question, and the methods of data collection and analysis so that another researcher would be able to evaluate and judge the decisions made about the data and findings. In narrative inquiry the researcher examines the interim text using the three levels of justification: the personal, the practical, and the social (Clandinin \& Connelly, 2000; Lindsay \& Schwind, 2016). For this study the researcher provided an audit trail which included digitalrecordings, transcripts, and notes. The researcher's dissertation sponsor reviewed transcripts to provide auditability of the data. A qualitative narrative approach emphasizes the perception of events from the participant's view and this represents a main component of validity (Riessman, 2006). The researcher ensured accurate documentation of all steps, procedures, and data obtained through the research process. 


\section{Risk and Benefits}

It was understood that participants in this study might experience certain risks or discomforts due to the sensitivity of the phenomenon being studied. Participants might also be anxious that their privacy might be violated since personal information could be disclosed during the study. To protect participants, the interviews were conducted in a neutral, private space. To further protect participants, all data from the interviews, including audio recordings and transcripts are being kept in a secure place that only the researcher can access. As part of the written informed consent process, participants were reminded that all information is confidential and that they may withdraw from the research study at any time without any repercussions. To protect the identity of the participants, each participant was given a code name before the interview began. Although the risks from participation in this study are no more than those experienced in everyday life, it was understood that AD nursing students might experience anxiety when discussing the phenomenon of academic misconduct. On the other hand, while there was no immediate benefit to the participants, both the researcher and participants may experience growth, self-awareness, and find new meaning in their story. This process may also influence future nursing students which in turn, may lead to benefits for their patients.

\section{Summary of Chapter}

Through this research, the researcher sought to give voice to nursing students' stories of the experiences of $\mathrm{AD}$ nursing students and academic misconduct during their nursing education. The qualitative method of narrative inquiry was used to uncover the meaning of the experience of the phenomenon of academic misconduct. The qualitative method of narrative inquiry was used because it is deemed best for capturing the detailed stories of life experience. 


\section{Chapter 5}

\section{Findings}

The purpose of this study using narrative inquiry was to gain a deeper understanding of AD nursing students' stories of their experience of academic misconduct, either through participation in or witnessing academic misconduct during their nursing education. The primary research question guiding this study was: "What are the stories of Associate Degree nursing students with academic misconduct experiences during their nursing education?" Researching associate degree nursing students who have experienced academic misconduct during their nursing education gives voice to the previously untold, unique stories of participation in or witnessing of academic misconduct.

\section{Participants and Procedure}

The sample included participants who were current associate degree nursing students who had witnessed academic misconduct during their nursing education. Seven interviews were completed of which five were usable. One interview was not included in the analysis due to the fact that the student did not understand the question and spoke about experiences in the clinical setting. The second interview was not analyzed as the participant was not an AD student. In all, five participants' stories were analyzed.

All five participants were women with an age range of 21 to 47 . The participants were recruited through purposeful sampling from public and private institutions in an urban northeastern city in the United states of America between September 2017 and April 2018. The collection of data took place at multiple locations within this city. The volunteer research participants engaged in convenient, prescheduled interview sessions which were audio-recorded. All participants reviewed and signed the Informed Consent Form (Appendix B), which was 
approved by the College of Staten Island, City University of New York Institutional Review Board, and included consent to be recorded, prior to beginning the interview process. A financial incentive consisting of a \$10 metro card or Dunkin Donut gift card was offered to the research participants prior to the interviews. The interviews were conducted by the researcher and the audio-tape recordings were later transcribed by a professional transcriptionist who had CITI certification. Table 1 provides a summary of participant demographics.

Table 1: Demographics of Research Participants

\begin{tabular}{|c|c|c|c|c|}
\hline $\begin{array}{c}\text { Assigned ID } \\
\text { Number }\end{array}$ & Pseudonym & Age & Gender & $\begin{array}{c}\text { Semester in AD } \\
\text { Program }\end{array}$ \\
\hline 1 & Alicia & 22 & Female & Second Semester \\
\hline 2 & Vanessa & 47 & Female & Fourth Semester \\
\hline 3 & Rachel & $30+$ & Female & First Semester \\
\hline 4 & Eileen & 21 & Female & Third Semester \\
\hline 5 & Melissa & 30 & Female & First Semester \\
\hline
\end{tabular}

\section{Collection of Stories Through Interview}

In narrative inquiry the data can be obtained through either field texts (living with the participants) or through hearing their stories (interviews). This researcher, who is a woman will be referred to as she, used interviews to obtain data. As a narrative inquirer, the researcher must be mindful of the relationship that was built between herself and the participants. She must pay close attention to the way she and the participants are positioned in the three commonplaces of narrative inquiry (temporality, sociality, and place) throughout the entire research process (Clandinin \& Connelly, 2000).

The primary research question for the study was: "What are the stories of Associate Degree nursing students with academic misconduct experiences during their nursing education?" The opening question used during the interview was "Tell me your story of academic 
misconduct." Probing questions were used to provide additional data to the initial question (Appendix D).

The interviews took place in private, confidential, and comfortable rooms, which provided a relaxed atmosphere to encourage the participants to be open, build rapport, and develop a relationship with the inquirer. The inquirer listened intently while the participants told their stories and concluded the interview when the participants indicated they had nothing further to add. The interviews lasted between 60 and 90 minutes. The following is a write up, reflection, and analysis of the interviews and the stories of each participant. The researcher read and re-read the transcripts, listened to the audio-recordings, and referred to her reflective journal to create the reflection and analysis. The participants were given pseudonyms to protect their privacy.

\section{Alicia (\#1)}

Alicia is a 22-year-old AD nursing student in an in a large public university system. Alicia contacted me after I presented my research study at her school. Alicia and I discussed a meeting time and place that was convenient for her to meet and talk with me. On the day of our scheduled meeting, I was running late and Alicia waited for me, which was very gracious and also indicated to me that she wanted to tell her story. Alicia is a second-language student, she appeared calm in her demeanor when speaking with me.

\section{Alicia's Story}

During my education, including primary, secondary, high school, and college, I have witnessed academic misconduct. Although I did not attend high school in this country, I myself participated in academic misconduct in high school. 
Since joining the nursing program, it is a little different from my other classes. The program has very strict rules for taking exams. But I don't feel like the professors always follow the rules. The professors will say you can't leave while taking an exam or you can't have your cellphones or stuff like that, but I still see some of the students using them. Last semester I remember a couple of my classmates taking pictures of the exam during the review. Once we finished the test we hand in our Scantron [and] we review the test. Since I saw people taking pictures of the test, of course, I'm not going to report that. But [what]I did was say to those students you should send me those pictures. So even though the exam was over, I have to get those pictures after the exam, because they really help with the final because everyone knows that the final has the same exact questions, not even the options were worded differently, no the same exact questions.

I am always afraid of being caught but I don't even think about it. But since I already knew there were people taking pictures and some of my friends were the students taking pictures, I was like you better share those pictures with me too. I really don't see it as cheating because I really didn't look at the pictures. I went through them but I didn't purely study from it. So during my review sessions with my classmates, I feel like I know the most. I am able to explain stuff and do all of the stuff we need to know but in the end they all get better grades than me, and I can't say anything about the pictures because I am somehow involved.

That was last semester, now it is different, but you know like, those rules that the professors make up they don't really follow because they tell us not to have our cellphones, so why don't they make sure we don't have our cellphones. Sometimes they make you put your things up front or put you stuff away and still you have your things in front of you. Also in my microbiology class, I don't know what happened but I knew one of my classmates, she got 
caught and she was crying in the bathroom because she might get kicked our or something. But then at the end of the semester, I don't know, she was all nice with the professor and I don't know what happened but she was still there. I don't think anything happened. I felt like after that experience I wasn't going to judge anyone by their grades, and I'm not going to let, you know myself feel bad because I know how they got their higher grades.

I know what my issues were. Maybe I didn’t approach the question the right way or study enough, but the thing is like before the semester started right, the professors would tell you like half of the students failed or they got a really low grade. The professors are like you shouldn't aim that high, or things like that, or maybe if one of my classmates did better than me at least I would know what kind of student they were and I wouldn't make myself feel so bad, but before all of this it was really bad.

I don't know why, but before nursing, from my other classes, right I would report if someone was cheating. I would see their stuff on the next table, and my classmates would be doing stuff that I saw and saw them cheating, I would just email the professor after the exam. I didn't have any problem doing that, but I don't know why but in the nursing program I don't do that everybody wants to pass, and I want my classmates to pass too, but sometimes you know, you know how they get their grades.

So we all agree that nursing questions are way different. Like you know, the way the test is it's different and sometimes we have to like take as many questions as we can in practice to just get the feeling you know, of how the questions will be worded. But if you already know how it's going to be, you know, of course it is going to make the exam a lot easier. I can't explain why it feels different for me in the nursing program about reporting fellow classmates, I always think like you know, they can't graduate. Like you know in the beginning of the 
semester, I don't think they are going to make it through. And if they do, I don't think they're going to make it through the NCLEX. I don't want to be the one who ruins it for the student, I don't want to be that one.

Sometimes professors, they have a preference towards those students that score higher, who do better in lecture. This bothered me in my first semester but now what I am trying to do now is not really report, I am not reporting anyone. But I am trying to make the professor aware of me and let the professor know I am doing my best. Like you know I am trying to participate more and trying to gain some approval from my professors. So even if I don't score that high on a test I can at least do good in the clinical part.

I have asked my classmates why don’t you just study, you know? They always say studying is not enough. They do their job, they do and sometimes they say they are not good test takers, you know and they don't have those skills when it comes to test taking and you don't always see the things you are learning about in the classroom in the hospital. The professors ask those questions, no one knows or remembers those things, so who cares if I just know what is on the exam and sometimes you might think, oh, well its true you know and you ask the nurses the questions and the nurses don't really remember or know.

There is some stuff, like really specific on the exam, that the professors want you to know and the students write their stuff and try to cheat on that, and they say it's impossible you're not going to remember that when you graduate. So it's like it's not going to do any harm, you know. The nurses don't remember so yeah so I am like ok good thoughts, irrational. I think because the fear of failing the course is greater than the fear of getting caught. Yeah they are like you know it doesn't matter which program you come from, everybody is going to take the NCLEX. They can get a job, so that's like the ultimate goals. So then oh, ok. 
Another thing is maybe it's not directly cheating and less common in the nursing study but most common is copying homework. It's so annoying that for instance we spend so much time doing the homework and then your classmates will be like can I see your homework, and you're like I didn't do it yet and they say it is due tomorrow, and I am like I am still doing it. They don't believe that you didn't do the homework yet. It doesn't make me feel bad unless I see the professor, you know, like, good grades, or can you please come up and you know read aloud so you know who didn't do the work.

I think because the nursing groups are small you feel like everybody has their own issues and struggles, but we all have the same goal. We all want to get the degree, pass the NCLEX, get a good job and you know hopefully, like what we're doing. Because you know, get paid is one thing and they you know liking what your doing is another thing.

I don't think students think about if they will have enough knowledge when they graduate. I don't think they ever think about that. I don't, like well, after my second semester, if you pass the class you realize that, OK I have to do those kind of things. If you're OK with it, I think they will be ok along the way, but I think they just don't worry about that. I think they worry about what they are going to make and whether they can find a job with an associate's degree or not.

Now going back to the beginning I just with that whatever the rules the professors have in place they should just like stick to it and you know follow it. Yeah, right now we have an issue because we changed the test type, the format. Now it is going to be computerized so we are all worried about that because we will not be going through the exams or stuff like that. We are going through a lot of changes and maybe the rules might not qualify for it, but even so, you know I know it sounds mean but if one of us gets caught the chances are they may have already 
cheated a couple of times without getting caught. Or if you are the unlucky one that gets caught on the first try then you know the rules say you might be on probation or whatever, I want to see that.

One of the things that in professor-wise tips, I would say that the lecture class is a waste of time if you're going through Power Point slides because, you know how a professor says oh we are here to help you, to guide you to answer those questions that you might have. So I agree with that, but I don't understand why they're going through Power Point slides, and of course, its so much material, you are not going to incorporate the whole Power Point, and we are responsible for knowing all that information that the professors cover in class and the professors don't cover everything in their lecture class. So I have a couple of classmates and myself, we all agreed that instead of using those three 2 hours of lecture class, why don't you just come up with, like cases and do that about the topic of the lecture.

The professors should use the class time to do case studies on the topic to see if we are doing our readings. Professors tell us that they are here to ask the questions and see if we have any questions, but no they come here and they waste our time reading off the Power Point slides and that's what they would cover the entire thing which we know it isn't going to cover the whole thing. So why don't professors take the time to make cases and see if we can answer the question, and that is going to help us on the exam. The professors should do a short lecture and then have 30 minutes or one hour to divide in groups then present the problem, what's the question? what would you do? That has to do with the lecture class.

But in regards to academic misconduct it is hard to tell in the nursing program, but I know it's happening. I don't really know if having someone, like an upper-classman telling you what the questions were I don't think that's bad, but still it's unfair. Why? because her, we have 
something that's like a mentorship program, so if you are signed up, they'll give you a mentor which is an upper-level student, and they usually keep track of, like, questions that were in the exam, the things you have to know, the textbooks and stuff. Those are like a great help you know, sometimes you don't want to buy a textbook, and you get the PDF form.

This is good for the students who have the mentor, for instance I have two mentors, but I don't know them because they haven't contacted me yet. But there are mentors that are active. You know, like proactive, and I have my classmates, they have those kind of mentors and they wrote down the questions that they were given in the previous semesters. These students have those questions but they don't share it. You know I know some of the questions, the professors repeat them on the exam, so I mean the school has the program of the mentorship program I don't know that they consider this a type of academic misconduct, but it's something that goes on.

So see these students are getting an advantage. Even though I have a mentor, they're not active. I don't even know them. They haven't texted me. But I know my other classmates, they have the stuff. They have the questions, the answer, and I know they appear and sometimes, like after the exam they say oh my mentor told me it was right there. I was thinking maybe I could have done better if I had the questions. And from other schools, my best friend transferred to a private nursing school and she has been telling me all her experiences, and I am telling her my experiences too. It is clear that in the private school, they don't want their students to have lower grades, and of course they're paying a huge amount of money, and she told me there's a thing called a test bank. She said she is using them in her classes and it really helps, we don't know about that here, I had to quit my job to help me do better, nursing is going to be my future job.

This makes me think about the future of nursing. You know I am like if this is happening right now in the nursing field, the nursing education, I'm like, I don't know what kind of nurses, 
you know, we're going to be if we are being taught like that. Yeah, like, you know, you always hear, like, oh nurses, some nurses know more than the physicians, and I'm like yeah because it's not you know, it's how you learn the stuff, you know? I sometimes question myself like any other student, like oh, am I going to make it through? But then people say to me oh they made it through why wouldn't you. I was like yeah, but it is still hard. So I have mixed feelings, I don't want to report but I kind of feel like uh-oh for the future.

\section{Reflection and Analysis}

Alicia's narrative demonstrates that she has some sense of what academic misconduct is. Indeed, her description of different events leads one to think that she has a good understanding of academic misconduct. She is sensitive that there is a difference in her feelings toward academic misconduct between nursing and non-nursing courses and that the ability of professors to follow through on policies may have an impact on the students and academic misconduct. Alicia seems to feel that the system in place within her nursing department gives mixed messages about the rules. Alicia seems sympathetic toward her fellow nursing students who may be participating in academic misconduct. However, she also seems to think that they will be found out one way or another, either by being caught while in the nursing program or by being unsuccessful on the NCLEX exam.

As the inquirer I must look at Alicia's story with the three commonplaces of temporality, sociality, and place. Alicia's experience takes place during her nursing education; although she does talk about being a student in grade school and high school and indicates that she may have participated in academic misconduct during that time. I think backward and forward, inward and outward about my own experiences in school and with academic misconduct, I am reminded that I also had experiences with academic misconduct during my high school education. The 
second commonplace of sociality speaks to the relationships of the participant. Alicia speaks of students, mentors, and other friends in nursing programs and how those social relationships may affect the way she feels about academic misconduct. Although, Alicia seems grateful for having friends in the program she does mention that "her friends with mentors may have an advantage over students who do not have mentors". The third commonplace of place speaks about the physical place where the occurrence happened, in a school setting in a classroom. We also meet in a place to talk about the experience. This space was chosen by Alicia and it is a comfortable space where we can talk.

\section{Three Levels of Analysis}

After reflecting upon Alicia's story, I think about the three justifications: personal, practical, and social. The first level of justification, personal, the narrative inquirer places themselves in the story. As the researcher if I situated myself in Alicia's story, I think I may feel angry. Although it appears some students may have the upper hand with their mentor situation, I am not sure that the majority of the nursing students have mentors. I am sure it is frustrating when you think that someone has the upper hand.

The second level of justification is the practical, how this experience will impact the researcher's professional practice. As I read Alicia's story and reflect upon it as a nurse educator, I need to be aware that there is a possibility that students are cheating on exams. Although we put measures in place to try and prevent cheating, there is still a chance that students may be participating in academic misconduct. After reading and reflecting I also have become more vigilant in ensuring that the department policies are being upheld. The students are very in tune with whether or not policies are being followed and this can lead to feelings of mistrust or unfairness by the students. As an educator, my approach to teaching and interacting with 
students is to be open and caring. This approach may create an environment of trust which may prevent cheating. This may be naive on my part as desperate times make for desperate measures. Students who fear they will fail may do whatever they feel they have to in order to pass a course.

The third and last level is the social justification. As the researcher I will take a step back and see how this may affect the students education and the care they will be providing for their future patients. As a nurse educator, I understand that cheating may affect students' knowledge base and the foundation of their nursing practice. If students cheat their way through their nursing education, will they have the foundational education necessary to provide safe and effective care for the patients for whom they will care? Will this ultimately affect patient outcomes? Secondly, will the students who cheat in school falsify or cheat while in practice? This second aspect could have a detrimental effect on patients, the facility that employs them, and society as a whole.

\section{Vanessa (\#2)}

Vanessa is a 47-year-old nursing student in an AD program in a large public university system. Vanessa approached me after I presented my research study to her class. She gave me her contact information and we agreed that I would contact her to discuss a meeting time and place that was convenient for her. We agreed to meet on a non-class day in a study room in the library. It was raining the day of the interview. I remember feeling somewhat anxious because I didn't want to be late being mindful that the student is giving up their own time to meet with me. Vanessa is a second-language student, she appeared calm in her demeanor when speaking with me and very intent on discussing her story. I was thankful that Vanessa agreed to speak with me because it was challenging to recruit participants due to the sensitive nature of the study. The library was quiet, with many students actively studying. When we found our quiet room we sat 
at a large round table. I began the interview by thanking Vanessa for agreeing to meet with me. I explained the consent and the procedure for the study, indicating that participation was totally voluntary. Vanessa signed the consent and indicated that she understood as we began the interview. She appeared relaxed and comfortable as she prepared to tell me her story.

\section{Vanessa's Story}

We usually take our exam in a computer lab, right, for second and third semester. Then a guy who recently graduated, I saw him, he was arguing with a girl right before the exam started that he wants to sit in the seat she is sitting in. Then I realized that students sitting in the front of the room were noticing because I usually sit in the back, I don't know if you saw our testing room it is like a library for us when we take our exam. It is like four rows of computer on the right and four rows of computer on the left, and then there is an aisle here, and there is like--the staff is at the back of the room. But faculty is keeping on walking through and doing stuff. I didn't say anything to the student and I just let him sit, but I was on the left he is on the right. I was thinking to myself how come this guy is trying to get into that seat? Because if-normally, if you are, if you have that kind of thinking, if somebody is seated on that seat, why are you going to push that you need to sit in that seat, you know what I am saying.

I didn't understand, he did not know the girl whose seat he wanted. It's not that they are friends or whatever, but I don't know why she allowed him to take her seat. Then after the exam a lot of my friends were telling me, Vanessa did you know what that guy got on the exam? And then cardio is the hardest exam, and I think he got 90-something, and people are saying that-how come he got that kind of grade? And then right after--I think a week after, we have another exam, and he got close, but you know that's fine. But that exam he got 90 something, and then it's like oh no. It's 88. It's high, right. So people are suspecting that he did something because 
he's trying to get that student's seat. I didn't know that it's possible to cheat on that kind of, whatever, arrangement because there was only one person in our batch--because I failed second semester. So I repeated second in the fall, but the semester I'm talking about, is like spring 2017, right. So I have--that person is my friend, the one who is always high from the second semester, she is always A minus. Her grade never went down. So even people are failing or if more than $50 \%$ are failing her grade is still $90 \%$ on each exam consistently from second and third semester. So now she usually sits on the first aisle close to the window. So I didn't know- -I was told, I didn't know that you could see the person who is diagonally to the person you could see their screen. I didn't know because we have screens on our computers so that you couldn't see the screen but if you sit diagonally you can see the person's screen. So if you sit diagonally to the person you want to copy from you can see their answers.

So if Deidre, my friend is seated on the aisle, then the guy seated on the third row diagonally he could possibly see my friend's test. I didn't know that you could do that. My friend sits in the front and I sit in the back so I didn't know that you could do this. But people are saying that he could see her screen. This guy is probably saying that I need to pass no matter what because he already failed once in first semester, something like that. It's like desperate stuff. I had that kind of notion when he talks that he is not impossible to do something like that because that's the way he is right.

So after I learned about this I emailed the professor. I emailed three professors and including the coordinator for the semester. And then I said to them that there probably is, like cheating going on in the class. I didn't mention the name about probably next time, I did not tell what it was but I said I didn't know that it was possible, but I heard that the person has to sit, like, diagonal across--diagonal at the back of the person. I mentioned my friend's name because she's 
the target where you'd want to copy from, right, but I did not mention the person who I and everyone else thought was cheating.

The professors emailed me back thank you Vanessa for telling us something like that. I'm just --I'm suggesting that maybe next time you will--what do you call that? Because it's a computerized exam, they can change the sequence of that thing, and they will probably assign seats. Not because before, they allowed the people just to sit anywhere, right. So from that time on, I think, after I informed them, they decided to just assign us, but not me. They- -because I usually just sit in the back, so I'm doing myself at the back, so I don't- -so I am not bothered by anyone else. But the rest of the people, the faculty usually assign the seats. So they created some changes in order for this nothing not to happen anymore.

But I don't know if they investigated, but I'm just saying what I thought should be right, because I said- -since I was probably [in] grade school, all my classmates are cheating--were cheating then. I was in grade one or something. I never--had that kind of--something, like moral stuff at that age that I don't want to do something like that. So even though I finished med school, I was a medical doctor in my country, but as long as I can remember I never remember myself cheating on anything like that in academics or anything or anything. So that's why I carried it over even until now I was here. So when I see something like that, I warn the professor every time.

In my first semester I did the same thing because I heard that we--our exam before, in first semester, is in the big lecture hall, but it's like, one step up. Every time the group of rows go back they are elevated from the group below, do you have a chance of looking at someone's paper. Not the same position, but the same thing as the diagonal. I heard some people are doing 
that as well, so I emailed the professor from that class too that on the final they should rearrange, and they did rearrange.

So every time I give them, this is the second time I give them a suggestion I did it in first semester and I did it again in second semester the faculty follow what I said, that maybe it's better for you to rearrange the positions the students sit in or you just randomly assigned seats but I usually sit on the back row when the exam is being given I usually sit close to the aisle on the right in the big auditorium. That's where I sit before, but they put me in the front which is fine, because everybody should be randomly assigned seats.

So that's what happened, so first and second semester. Even though I actually did not know, I had just overheard, but I didn't know if it's really what happened, but I have a feeling something that they're going to they have a cheating arrangement or whatever it is. That's why I emailed the professor. So that's what I did. So every time I hear something like that, I warn the professor and they listen. If I did not do something or say something to the professor I would feel guilty, but right after doing that, I feel good about myself. So that's what I'm saying. It's like my conscience is clear. If I know something I don't say anything to anyone else but I told the professors. I am consistent in that way and I never regret anything that I decided on that I just did it.

The thing is if people are observing it and I did not know it because I don't pay attention during the exam, I'm focusing on my thing. I'm not I don't know what they do, but people are saying that students are cheating I feel I have to do something. It also makes you wonder how someone scored that high on the exam because it was the hardest exam. My friend who the person was trying to cheat off of I think she got a 95 or 96 on that exam, she is the one they are targeting. They want to sit diagonally at her back or something. My friend just graduated so she 
is good. But I warned her when I heard about this and she decided to sit in the back from then on. She is not sitting in the front anymore, because if you are in the back no one can cheat from you.

But if you are in the front or something, there's a big chance that you are like, tempting people to do that because they know that if you consistently get good grades you may be tempting people to cheat from you. So it's like if you already know that people are trying to do that, you maybe should try and avoid it by moving your seat maybe by placing yourself somewhere that people won't be able to cheat off you like in the back. So my friend asked the professor if she could sit in the back of the room. She defended herself saying that she didn't know that some students were trying to copy my stuff, and because I mentioned her name to the professor, but didn't name the person trying to cheat from her she changed her seat.

So that's the whole thing. I that's the only two things that happened, I think. There is nothing more that I remember that is everything I know. I try to do something before something happens again. I feel the same after each event. Because I feel I am obligated as a person to do what I think is right. So if I think that something is not right, I have to do something. Oh, there's another thing. The friend of that person, they are sort of they are my friends too, right, and they are working with me in one of my tutoring here. So they study in that place because they're studying for boards, right. That person who's the friend of the guy that was cheating, she told me "Vanessa, did you know that you can cheat using your watch? We wanted to tell you." I said I know. It's OK, I'm going to...so she just gave me the idea again, right I almost emailed the chair because I said "I have something that you can cheat on the watch, but I wasn't sure how many people in our class have this watch. If it's me, I don't have a problem I will leave it in my bag-- I 
was thinking there are not many students that have an Apple watch. You can only do that if you have a smart watch not a regular watch.

But what the chair did, before the exam, she said, "Oh, everybody please remove your watch, even the one that is an analog. "Professor, this is just an analog". The chair said we have a clock right here you don't need to wear your watch. Ok, you can just put your watch in your bag, and the rest of us we just put our things in our bags. The professors then check our ID and give us paper and pencils so we can take the exam.

So I was thinking that I was supposed to email the chair to warn her because I heard from that girl, right, but the chair said that on your NCLEX exam you will not be able to have your watch, you will have to remove it before you take the exam. So let's just do this now. So that is what she said, I almost emailed her. Well, that was fine, right. So if I learned something from people that, oh, you can cheat something like that from that, I want to I'm giving them the information because it might be their doing that before, you know what I'm saying. That's what I am doing.

The nurse educators must have trusted me because they know my ethics stuff or probably they trusted me or something, because every time I give them suggestions, they do it. Even though they don't reply to my email, they will say nothing or they just say thank you. That's it. They will not say anything at all, right. But they really do what I am suggesting.

So that's a good thing, you know, but probably if other people do that to them, probably they will have second thoughts or hesitation that what is the purpose of this person telling us or something like that. They never questioned me every time I warn them they just do it. That's good, I feel a sense of accomplishment because you are trying to do what is right and they don't ignore it they really did something. After this the chair of the department keeps warning 
everyone. She is not supposed to be in the exam for second semester because she teaches a different semester but after I emailed this professor she goes in before every exam and tells the students, "Remember guys, if you are going to plan to do something, it is not worth it because you are going to take the risk of not becoming a nurse." So I know that my classroom professor probably forwarded my email to the chair, and she keeps telling the students it is not worth it to cheat because you don't want to get dismissed from the program.

So now we are not able to look at the exams because they changed the sequence of the questions, even though they may be the same questions they are scrambled in the exam. So again this is a suggestion that I made and they listened to that too. But you can still see the exam of the person who is diagonal from you. But if the questions are scrambled you won't be able to cheat. But people do a lot of things when it comes to cheating. You know what I'm thinking whatever your values are and of course it affects you because you are implementing or its hypocrisy because you are not doing what you are saying. If you are the kind of person who has integrity it may make it hard.

Even before I got into this program, no matter where I go, it's going to be applied in my life. It's integrated in my being. It's not separated with me, so that is the reason why I reported the incidents. Because if I didn't it would go against what I believe is my integrity. Because I do have that kind of integrity I can't let it pass. I had to do something, so that's the reason, my integrity was at stake. Your integrity has to be implemented. If you have that integrity and you are a practicing Christian then you have to stand up for what is right. I try to be nonjudgmental of the people who cheated because you have to give them the benefit of the doubt. Also you have to be nonjudgmental of your patients. I want to give them the benefit of the doubt because they are my friends. I see them studying every day because they are preparing for the NCLEX. 
I always see them from the last week every day because we are in the same place. They usually call me or call on me because there are some chemicals the professors hardly explain or pronounce and because of my background the students will ask me to say them. I think he is fond of me. I think we have developed a friendly relationship, and even though in the back of my mind I am thinking about the other thing. I think some of the students also feel the same way but for some reason I am still able to have a friendly relationship with him. I do not discuss this situation with other students, just the student who told me about it. I try and give him the benefit of the doubt and that is why we don't have any issues. He is always asking me about my niece, my niece goes to this college and he knows that my niece has some mental health issues. He is always encouraging to me telling me what a great job I am doing with my niece. So even though I know what he did we still have this friendly relationship and there are no issues between us.

I don't think that any students feel that they are not prepared for practice because we have a very rigid program. Like when we are in the hospital, we are performing like a nurse we are doing some of the things that a nurse is doing except we are with our professor and we don't have the RN license yet. So I have never heard people or anyone who got a degree from this program complain or say that they're not ready to practice as a nurse. I never heard anyone say that. We know what we are doing, we are new but we know, they really prepared us for this.

Even though that student cheated on the exam he is knowledgeable. He, probably feels that he will prove himself after. I know that he is studying well, but probably he doesn't have the confidence or that he is desperate to pass because he cannot fail the course because it is his second time taking the course, and the second time you are taking the course you are not sure whether they will accept your appeal or not. Because the rule is after one failure, the second 
time you must pass the course. I have heard of exceptions but that is the rule. I know that some students repeated more than twice but this is the chair who is deciding and it may be politics.

But I was thinking how come the chair would decide, unless the professor from that particular class was the one deciding. The professor was the one supervising the student, so the professor may know better about the student. I had one student in my clinical, she failed in the third semester but she also failed in the second semester and they allowed her to repeat. So it's like where is the rule, right?

But the thing is, in the semester that I told you about the cheating, that is the semester that I failed. But I still don't regret emailing the chair that someone may be cheating. I have no regrets about failing the semester either; although students were shocked that I failed, students were shocked that I failed third and telling me that I should appeal to the chair because they feel I am smart. Some of the professors were even surprised that I failed because they know that I know my stuff. But I know that failing is on me. I know what I did not do and what I did right. I wasn't really reading the books and focusing and stuff like that. So its fine. But the thing is that it's like a test for me, that even though I should say probably in my prayer to God I would say that the student who cheated passed and I failed. How is that fair? My husband also said the same thing, how is it fair you are doing the right thing and you do a lot of service for God and you failed and the other student didn't.

The semester I failed I was involved in too many things, I sing in my church, this is the fifth year. There was no one to sing during mass so I volunteered. I was also teaching religious education to third and fourth grade students, so all of my weekends were busy. I was also the SNA vice president that semester. So I was waking up at 3 am because my clinical is far from my house and I have to be there by $8 \mathrm{am}$. So that semester was very difficult for me. I would say 
that my studies suffered when I was doing all of those extracurricular activities. My husband kept asking how come you failed when you are doing all of these services for the Lord? I did not even fail big time, only by 0.9 points. So I realized that I might have to give up some things, because I was also doing a prayer group on Fridays. So I shared all of that with my prayer group and my prayer group said God is telling you that this is your career and he does not want you to fail, so he is probably giving you a warning that you should give something up. God knows that your heart is with him, and you are serving him but you have to spend more time studying and that is what he probably wants you to do. So after that I called the director of religious education and told him that I could no longer teach. I still sing in church and do my prayer group but I am much more relaxed now. Before I was even working on Saturdays, I did not have one free day. I'm telling you every all my days from Monday to Sunday is planned. I had no free time to study. I only failed the course by 0.9 points.

My classmates most of them are not married and do not have as many responsibilities as I have, I have a lot of responsibilities. I feel the student that cheated was just afraid, that he will not pass. Because on the second time you take the course you have to pass. But because I am a person of faith [I] rely on God's will and I don't question it. That's why it was different, I accepted my failure and actually said to myself that failure is going to be an example of role modeling for others. Even though it is a test of faith especially because I was a doctor in my country.

It is not easy but because I know God used me for that failure in order for me to be an effective follower of him is to surrender to him and remain in my humility. I feel God used me for this reason so that I may be more effective bringing him to people because I am not inflated, I 
know what my achievements are and I have a good experience in work. Anything that is related to health I had that before coming into the nursing program.

I am one of the only students who did not apply for the nursing program on my own, but I had a professor encourage me to go into the program because the professor that hired me as a math and biology tutor for pre-nursing students suggested I apply to the nursing program, and that professor knew me before I got into the nursing program.

I never thought about becoming a nurse before so I finished my health science here, and nursing will be my fourth degree. I finished my bachelor's in biology and the medicine, and then health science here and then I was thinking of going into a program but now I am in the nursing program. Some people are surprised that I am becoming a nurse and said I wasted a lot of time with my other studies. But for me, if I at least know that God is the one who directed me to do it. It is his will not mine. I was thinking about becoming a PA but with nursing I will be able to take care of my niece because she was just discharged to me, the one with mental illness. There is no way that I would give her up and put her in to the foster care system, my conscience could not let me do that.

This is one of the reasons why my professor said to me "Vanessa why not apply to our program?" I said, me become a nurse? But I did not question her advice and I applied, was accepted and here I am. That's what happened. So that's the thing, I love all the things that I have in my life, is God telling me he wants me to become a nurse and not a doctor. And this makes me happy especially for my niece. She is my greatest accomplishment and she is doing well. Two years she is in a psychiatric mental institution. Two years after that she's in community resident, and now it looks like she is alright. If I don't tell people that she has mental illness they will not know. She has come so far. Even her teachers say I did a great job. 
There is nothing else I would like to add to the story of academic misconduct. What I am saying is the one that I reported about shows what kind of character I have. I really live whatever I believe is right that is what I do. I am happy with the result and the person who I reported on never knew that someone had reported it. I am not worried that the person might know who reported it. There is a camera on the computer so the professors could review whatever they want. But my thing is the person really studied and tried to prove himself after that. So I think that he is proving to himself that he knows his stuff and deserves to graduate and take the NCLEX exam.

\section{Reflection and Analysis}

Vanessa opened the interview making it clear that she never participated in academic misconduct. She discussed this point throughout the interview. Vanessa speaks about witnessing a student arguing with another student before an exam to sit in a particular seat. The student gets out of the seat and gives it to the student who is asking to sit there. Vanessa witnesses the argument but has no idea that you would be able to see another student's computer to cheat on the exam. Once the exam is completed, Vanessa is told by some of her classmates that the student was cheating and when the grades are posted the student received a very high score on the exam. Vanessa feels the need to alert the professor and the chair about this possible cheating. She feels a moral obligation to report the incident based on her belief system. Looking back into her childhood, Vanessa tells stories of feeling the need to do the right thing when her classmates cheated. This brings me back to my childhood when my parents would have me apologize for doing something wrong, to make sure I understood the consequences of one's actions. Vanessa reports that if "she does not say anything she will feel guilty"; she relates not being judgmental about her classmate to the non-judgmental care a nurse provides to patients. 
She states, "I will have to have a non-judgmental attitude to provide good care." Vanessa also speaks about integrity and how as a nurse "we have to have integrity to provide safe care for our patients". Vanessa discusses the fact that even though the student may have cheated on the exam, "he did prepare for the exam and probably would know what to do upon graduation from the program". The NCLEX would prove his abilities after graduation.

Vanessa talks about how it made her feel good that professors changed some policies regarding test taking after receiving her email. She states " the nurse educators must have trusted me because they know my ethics stuff or probably trusted me or something because every time I give them suggestions they do it". She talks about the desperation students may feel if they are repeating a course, because if they don't pass, they will be dismissed from the program. The topic of following through on department policies comes up as Vanessa shares how some students may be allowed to continue and some may not. Vanessa perceives this as a discrepancy in department policies which is a concern for her. Vanessa also had to repeat a course and although this made her feel anxious she states "she has no regrets". She needed to re-evaluate and learn time management and prioritize what she could and could not do to be successful in the nursing program. Throughout the interview, Vanessa speaks about her "commitment to doing what is right and a sense of accomplishment and integrity that helps her feel she has to do what is right".

As the narrative inquirer I reflected upon Vanessa's story using the three commonplaces of temporality, sociality, and place. Temporality includes the time that something takes place. Although Vanessa's experience takes place during her time as a nursing student she also brings to this experience other times in her life when she did the right thing. Vanessa brings those past experiences with her to the current decision to report the incident. I think backward and 
forward, inward and outward about my own experiences with doing the right thing or having to take responsibility for doing the wrong thing and how the two situations made me feel. The second common place of sociality speaks about relationships. Vanessa appears to be well thought of by her classmates as they feel comfortable enough to tell her what they witnessed, possibly knowing that because of who she is she may feel compelled to report the incident. The third commonplace is place. The initial experience takes place within a school setting. Vanessa vividly explains what the room looked like and how the situation could have happened, and then how reporting the incidence led to the policy being changed.

\section{Three Levels of Analysis}

After reflecting upon Vanessa's story, I think about the three justifications: personal, practical, and social. The first level of analysis is the inquirer, situating himself/herself in the study. As the researcher if I situate myself in the study, I would probably feel angry that a student was cheating on an exam, especially if that student scored higher than me on the exam. I may feel frustrated because I studied and did not score as high as the person who cheated on the exam. This experience is similar to my experience in high school when one of my friends cheated on the regents and passed the exam while I failed, this made me very angry. While in high school I did not report the student, as I have grown and evolved as an individual I may better understand the ramifications of cheating and may want to report the incident. I am not sure what I would do but I do know I would not want to be seen as a snitch. Although there is no way of knowing if the students knew that Vanessa reported the incident. Vanessa does not believe the students know that she said anything and she also did not give the student's name.

The second level of justification is the practical, how this experience will impact the researcher's professional practice. As I read Vanessa's story and reflected upon it as a nurse 
educator I need to be aware that there is a possibility that students are cheating on exams. Creating a safe environment for all students taking the exam is extremely important. Assigning seats for the exam will prevent friends from sitting next to each other and students choosing a seat for a specific reason. As the educator I will also make sure that the questions and answer choices on an exam are randomized. Although nothing is fool proof this may foster an environment of integrity which may prevent students from cheating.

The third and last level is the social justification. As the researcher I will take a step back and see how this may affect the students' education and the care of their future patients. Cheating may affect the students' knowledge base and the foundation for their nursing practice. Will students who cheat their way through their nursing education have the foundational education to provide safe and effective care for patients and how will this ultimately affect patient outcomes? Secondly, will students who cheat in school falsify or cheat while in practice. This would have a detrimental effect on patients, the facilities that employs them, and society as a whole. Nurses are considered the most trusted profession in the country. If patients lose that trust it will become very difficult for patients to feel safe in a hospital or under a nurse's care.

\section{Rachel (\#3)}

Rachel is a $30+$ year-old AD nursing student in a private nursing school in a large urban northeast city. I met Rachel after speaking to nursing students at her school about my research study. Rachel and I met in a private conference room at a mutually agreed upon place. I welcomed Rachel when she arrived and we sat across from each other at a large conference table. Rachel seemed relaxed but eager to tell me her story. I explained that participation was voluntary and that she could leave or withdraw at any time. I then reviewed the consent and 
demographic form with her. She signed the consent and said she had no questions so we began the interview.

\section{Rachel's Story}

I myself have never had any misconduct, I think that cheating is wrong. It's ethically wrong. It's wrong to get through school that way. I did witness a couple of people cheating, it was very blatant and out in the open. It was totally shocking to watch. We were taking a nursing exam. The room we were testing in was divided into two groups, every other seat was a student from a different class; I was sitting in-between two students from a different class. I had known the two students to be upstanding individuals and nice people who I never thought would be doing something like this in the middle of an exam. They started whispering to each other, "A,B,C," and the like, comparing answers. I just sat there and said to myself, "Are they doing this right now?" No teacher was around because sometimes that doesn't happen when there is a teacher nearby.

I turned to them and said, "What are you doing?" They kind of slowed down after that but then they continued. It was really hard for me; it was very distracting. It was very difficult for me to be in the middle of that, it was so unethical it really bothered me that someone would do that. I was shocked. It made me feel horrified that someone would make their way through nursing school like this. Nursing is an ethical profession, and to cheat your way through school it is very upsetting. Even if they knew the material and they were just checking their answers, it still isn't right.

When I said to them what are you doing I wasn't worried that anyone would think I was cheating because they weren't in my class. I think I was definitely changed by this experience; it bothered me very deeply, I couldn't stop talking about it, I was telling everyone. I just couldn't 
believe it. It made me realize how strongly I feel about cheating and the ethical part of it. It also changed the way I felt about the two students who were cheating. It made me think about them differently. I assume that there is still cheating going on. I would think if the students think that they could get away with it, they would continue to cheat.

As far as nurse educators and cheating, I think that nurse educators are very aware that this could potentially happen, but then there's also the side of you that wants to trust people. The students are going to be going into a field where it is expected that they will do the right thing so as an educator you would hope that you could trust them. It is kind of a balance. We have to trust the students enough but we also have to set limits and maybe get more proctors to watch. During my experience, I was sitting there, and the teacher was in the front of the room. I was all the way in the back, and it wasn't like the two students were whispering, it was very quiet it was very blatant. Maybe if we have more proctors, or different stations and have the proctors walk around and eyeball the room. If you are not actively walking around, you don't really know what is going on in the back of the room. I am not sure if we have different versions of the same test.

This has influenced my nursing education as far as the whole ethical part. I know how much it means to me and how important it is to the profession. It definitely made me feel stronger about that. I was aware that students may be cheating, I have heard about it, but I had never witnessed it and it was so blatantly obvious. It wasn't like someone had heard a question before, overhearing students in the hallway; it was in the middle of the exam, the teacher is in the room and you're taking a test and talking to the person next to you to get an answer. Not just saying to the person "can I have a pencil, it was like what's question number 41." I felt that both of the students were wrong. I think you know someone could accidentally be involved if 
someone is looking at another student's exam and the person doesn't know. The person doesn't believe in cheating but is now involved. I feel that is a little different than actively asking someone a question and they give you the answer.

I am very happy that I was able to speak to you about this, it has very upsetting and I wasn't sure what to do. It wasn't fun for me being put in that position. I didn't report the incident because this kind of thing could jeopardize their whole nursing career. I wasn't prepared to make that sacrifice for them. I think that if they mess up at some point, they will get caught on their own, without me having to say something. I definitely struggled about what to do; whether or not to say something.

We don't have an integrity policy that I know of although we do sign something before each exam. But do people even read it? I feel like when you take more than one test, you just look at it, you sign your name and that's the end of it. You sign that you will not cheat but at the end of the day if you do cheat and no one finds out about it, how does signing a paper mean anything. It don't feel like it has much value, if someone is going to cheat they are going to cheat.

I think students are afraid to get caught, but they still might cheat. I don't think they are afraid to the point that they wouldn't cheat. We had an experience where two students had cheated and nothing was done. I don't know if they were penalized in a more private way but they weren't kicked out of the school. To me I feel like a way to teach someone is to do just that and show everyone else, even though it is terrible for the person getting asked to leave. That was another blatant incident so I feel like after that happened, it was just like, if you get caught, hope for the best and you probably won't get kicked out. Maybe the student may have to retake the course but they won't get kicked out. 


\section{Reflection and Analysis}

Rachel's story demonstrates that she has an understanding of what academic misconduct is and that she has never participated in academic misconduct. Rachel also talks about how this experience made it very clear to her "how much she is against academic misconduct, and that the ethical standards of being a nursing student and a future nurse are very important". Rachel speaks about being in the middle of two students cheating on an exam and how uncomfortable it made her feel.

As the inquirer I use the three commonplaces of temporality, sociality, and place. Temporality includes the thinking inward and outward, backward and forward about our interview. As I look inward I am thinking about the person who is stuck in the middle and how this must make a person feel. I ask if the individuals who cheat even think about the position they put others in. It also makes me reflect on my own education in grade school, high school, and nursing school. There were individuals who cheated. I often wondered about how they felt during an exam. I know it made me angry when I witnessed cheating. Temporality also includes the time that something takes place. While Rachel's experience takes place during her time as a nursing student, she also brings with her past experiences from life and her ethical position on what is right and what is wrong. Rachel expresses how this experience made her realize "just how strongly she felt against cheating". She always knew she was against cheating but this experience and being placed in the middle of it made her realize just how strongly she felt about

it. Rachel brings her past experiences with her to this experience, and she states "she didn't know what to do about it, and was happy she was able to speak with me because it made her feel better about the whole thing. I think backward and forward, inward and outward about my own 
experiences with doing the right thing or having to take responsibility for doing the wrong thing and how the two situations make me feel.

The second common place of sociality speaks about relationships. Rachel appears to have a good sense of who she is, and she did have a relationship with the students who cheated before the incident. This incident made her rethink her relationship with these individuals and how she felt about them as people.

The third commonplace is place. The initial experience takes place within a school setting. Rachel vividly explains what the room looked like and how the situation could have happened and then how the experience made her feel and the struggle she felt about what to do.

\section{Three Levels of Analysis}

After reflecting upon Rachel's story, I think about the three justifications: personal, practical, and social. The first level of analysis is the inquirer situating himself/herself in the study. As the researcher, if I situate myself in the study I would probably feel angry and surprised that a student would so blatantly cheat on an exam. I would be worried that a proctor may also think I was cheating because I was sitting next to the cheater. Although Rachel did not express this same feeling. I may feel frustrated because I studied and may not score as high as the individuals who cheated on the exam. I would like to think I would feel compelled to report the situation but I am not $100 \%$ sure that I would because I witnessed academic misconduct during my high school education and nursing school and did not report it.

The second level of justification is the practical, how this experience will impact the researcher's professional practice. As I read Rachel's story and reflect upon it as a nurse educator I need to be aware that there is a possibility that students are cheating on exams. Although we put measures in place to try and prevent cheating and have students sign an integrity statement, 
there is still a chance that students may participate in academic misconduct. Rachel speaks about signing an integrity statement before an exam, she doesn't feel it makes any difference, that students are just going through the motions. As an educator I must reinforce the importance of students' understanding of the document they are signing before the exam and the consequences that may result if they are found to be cheating during an exam.

The third and last level is social justification. As the researcher I will take a step back and see how this may affect the student's education and emotional well being. As a nurse educator, I understand that student's who may be caught in the middle of other students cheating, may have some emotional struggles after experiencing something like that. I need to be vigilant in creating an atmosphere of openness so students who experience something similar to Rachel would feel comfortable to come and speak with me.

\section{Eileen (\#4)}

Eileen is a 21 -year-old AD nursing student in a private nursing school in a large northeast city. I met Eileen after speaking to nursing students at her school about my research study. Eileen agreed to speak with me and we met at an agreed upon space near her school. We sat across from each other at a large table in a quiet room with windows looking out to a busy street below us. There was very little outside noise. Eileen had a calm demeanor but seemed eager to speak with me. After welcoming her and thanking her for taking the time to speak with me, I explained that participation was strictly voluntary and she could leave at any time. We then reviewed the consent. Eileen had no questions and said she was ready to begin the interview.

\section{Eileen's Story}

I just want you to know that I didn't participate in academic misconduct myself, but I did witness it in a biology course. So it was in a biology course. So there was always a little chatter 
going on during certain tests and I guess the professor was definitely getting frustrated and started separating people for the exams. But on the final, a group of classmates, where I

normally sit, you know how everyone gets their seat. So where I normally sit, by the time I got in on the day of the final, I saw kids were sitting in my seat, so, OK, I sat on the other side of the table. Then during the exam they were just full-blown passing written notes back and forth. I couldn't believe it. It was, like, a group of six kids and they full-blown cheated the whole time, through the entire final. And the professor would say definitely, like, “Oh, keep it down," you know, but he didn't do anything else. There was also one student that kept going in and out of the bathroom, so the professor at one point was standing at the door, paying kind of close attention to the student going into the bathroom, and not really focusing on the other kids that were passing notes.

This made me feel pissed off, but I also felt like it's not my business to say something, you know. I'm definitely am not that student to go tell the professor, oh, look at these kids or whatever, I wouldn't be telling on them. I can't fully say yes, and I can't fully say no if the professor was aware of what was going on. Looking back on it, I'm wondering did he turn a blind eye to them, you know? I want to believe he didn't, -- that he was fair to all of us, but I don't know. I can’t definitely give you a yes or a no answer.

During the nursing classes we have taken plenty exams. Even if someone thought about cheating, there is no way. I think it's totally impossible to cheat without definitely being caught. So I definitely feel like now in my two nursing classes that I have right now, there is no way. The professors make us leave our bags upfront, and no cell phones. We can't even have a water bottle on our desk. Nothing. As far as an academic integrity policy, I am not sure but we do have to sign a consent before each exam. Not a consent, but we're signing an Academic 
Integrity statement. So I'm definitely not signing if I plan on cheating because I would be petrified to get caught. So I definitely feel there's a little bit of a fear factor involved with signing the consent before the exam. It might scare someone out of cheating, if they signed the paper but I am not sure, I don't know.

There was another incident in a math course. Some of the students may have been nursing students but I didn't need that math course for this program, but maybe other students did. I didn't witness the cheating myself but someone did, and that student got up and told the professor right in the middle of class. I don't know what happened to that student, I'm assuming or I guess they got a fail? I don't know. But I didn't, I'm not going to lie I felt like she should've minded her business a little bit. So I don't know if that would help in any which way. I don't know. I definitely felt like she shouldn't have got involved, maybe because if I did something, I wouldn't want someone tattling on me. I don't know. Maybe because it wasn't a life-or-death situation? But it could lead to one because of nursing stuff. I don't know.

I did feel that there was unfairness, where all those kids got away with the cheating. I don't know what happened to them, maybe he could've failed them later. I don't know. But in that moment, I definitely felt unfairness. No, definitely the unfairness with my class. To be honest, I never thought about cheating because I've never really had a point where I needed to. If I did bad on one test, I definitely pulled it together for the next one, I have been in a position with bad grades but thankfully I have never had to resort to cheating. I feel really good about test taking.

As far as nurse educators addressing the issue of academic misconduct, I think they try different things, like the academic integrity paper, they make us sit separate and the books at the front, and no cell phones, so I don't feel there is any opportunity, there's no opportunity. And 
even when it comes to nursing, you can't even cheat because the questions, the way the questions are worded, even if you know the definition of something, you can't answer the question with just the definition, you have to have read the book or done clinical to understand what the question is asking you. Also you can't cheat in the practical portion of the nursing program so you have to know your stuff. You can't cheat on the NCLEX. I would say they could weed immediately, if you don't know your A\&P and you're failing those portions of the questions, then there's a possibility that you might have cheated in your A\&P courses. But I guess I don't know if there's any way to find out.

There are factors that may add to students wanting to cheat, such as outside pressures. Having children, going back to school as an adult, being away from the A\&P classes for so long, other life issues, jobs, certain things like that, you know, might force somebody to cheat in order to pass.

Also thinking about our exams, we are not allowed to review exams, we cannot physically see the exams. Except for one professor [who] says she has new questions for each exam. And there is no talking in the hallway between exams because they do one class after the other.

\section{Reflection and Analysis}

Eileen's story demonstrates that she has an understanding of academic misconduct and indicates that she has never participated but has witnessed it in multiple classes. Both classes that Eileen has witnessed academic misconduct were not nursing classes but pre-requisite classes for the nursing program. Eileen feels she would not report the incident because she doesn't feel that it is her place. Eileen talks about how this experience made her have feelings of unfairness and anger about the students who did cheat and possibly the fact that they did not suffer any 
ramifications. Eileen speaks about not being sure if the professor did anything about the situation or whether he just turned a blind eye to the cheating. Rachel also talks about how she feels that it would be impossible to cheat on a nursing exam, and that the professors are very vigilant in ensuring that no cheating occurs.

As the inquirer I use the three commonplaces of temporality, sociality, and place. Temporality includes the thinking inward and outward, backward and forward about our interview. As I look inward I think about the how feelings of unfairness may affect students as they continue with their education and wonder if such feelings may lead to more cheating within the class. The student who decides not to cheat must have a strong moral compass and conviction that cheating is wrong, no matter what. The story also makes me reflect on my own education in grade school, high school, community college, and nursing school. I vividly remember young men from the maritime school who blatantly cheated on a statistics exam. I remember thinking, "You are going to be driving huge ships, don't you think you need to know what you are doing and that cheating is wrong?" and watching them in the hallway before the exam, noting that it did not appear they thought that way. Temporality also encompassed the time that something takes place. Eileen's experience takes place during her time as a nursing student where she also brings with her past life experiences. Eileen talks about her never needing to participate in academic misconduct because she always feels prepared for exams and is a good test taker. Would her experiences be different if she didn't feel that way? This is in contrast to Vanessa's explanation of the young man who cheated because he was repeating the course and possibly didn't feel confident in his ability to pass the exam.

The second common place, sociality, speaks about relationships. Eileen speaks about how, when one student reported an incident during class, she did not agree with this action 
because she didn't feel that it was her place. Eileen must have social relationships with the students in her classes because she speaks about other students reporting academic misconduct to her. She appears to have a good sense of who she is and what kind of student and individual she is. The third commonplace is place. The initial experience takes place within a school setting. Eileen vividly explains what happened during both experiences she encountered. Although she does not go into detail about what the room looked like, she is able to describe what the students who were cheating did and what the reporting student did in the middle of the exam.

\section{Three Levels of Analysis}

After reflecting upon Eileen's story, I think about the three justifications: personal, practical, and social. For the first level of analysis, the inquirer situates himself/herself in the study. As the researcher, if I situate myself in the study, I would probably feel upset that a student would be sitting in the seat I had for the whole semester as we are creatures of habit. It might make me question why someone would want my seat when I have been sitting there all semester. I may also be annoyed that students are talking during the exam because it is distracting and I may not be able to concentrate. I might commend the student who spoke out because even though I wouldn't want to be the person who reports the incident, it might please me that someone has reported the incident and cheating students may get in trouble.

The second level of justification is the practical, how this experience will impact the researcher's professional practice. As I read Eileen's story and reflect upon it as a nurse educator I need to be aware that there is a possibility that students are cheating on exams. After reading and reflecting, I also have become more vigilant in ensuring that department policies are being upheld. Do students understand the paper they are asked to sign? Maybe I need to be more explicit about what academic misconduct is and how it could affect the student as a nursing 
student and ultimately as a nurse. It is stated in the literature, that students who cheat in school will likely cheat in practice. This is very alarming to me because it may ultimately affect patient outcomes and the way the public sees nurses.

The third and last level is social justification. As the researcher I will take a step back and see how academic misconduct affects students' education and the care they will provide for future patients. As a nurse educator I know that cheating may affect students' knowledge base and the foundation of their nursing practice. Will students who cheat their way through their nursing education have the foundational education to provide safe and effective care for patients? How will this ultimately affect patient outcomes? Second, will students who cheat in school falsify or cheat while in practice? If that is the case, their academic misconduct can have a detrimental effect on the patients for whom they will provide care, the facility that employs them, and society as a whole. as well as the patients for whom they provide care.

\section{Melissa (\#5)}

Melissa is a 30-year-old AD nursing student in a private nursing school in a large city in the Northeast. I met Melissa after speaking to nursing students at her school about my research study. Melissa and I met at a mutually agreed upon place and sat across from each other at a long conference table. Melissa seemed a little nervous when we met. After I welcomed her I explained that participation was voluntary, that all information was strictly confidential, and that she could leave or withdraw at any time. She seemed to relax a bit and signed the consent. She said she had no questions so we began the interview.

\section{Melissa's Story (\#5)}

I work hard and everything, to do well in school and then this person cheats. The person who cheats gets a benefit. The student who cheated is in the nursing program right now at this 
college. I am not sure if it is still going on I am not sure. I also am not sure how cheating in the nursing program will affect her work when she gets to the hospital. I am thinking that maybe cheating in the nursing program will affect her when she gets to the hospital, when she actually has to take care of patients, will she be able to know what she is doing when it comes to administering medication, will she know what to do.

I never participated in academic misconduct myself because I always feel like if I participate in cheating, then how am I going to understand the material myself. So I always like keep to myself, but honestly I will run jokes with students and say you know, let me look at your paper because you know it all. But at the end of the day, I will sit at the back of the class during the test. I will give them space but it doesn't make sense for me to cheat. They know I'm going to understand my work. I always understand it, when I finish a test and get to see my result, then I would say, OK, this is where I made my mistake when I go back to my professor, and then we will go over the exam with me.

When I witnessed the person cheating on the exam it made me upset, a little bit angry, but by the end of the day, what I'm going to say, it was not only her cheating. There was another student who was also cheating. They both passed, but my thing is what do they know. I kept quiet until the professor saw it because I think that the professor should be the one observing everything, I'm just a student, it should not be my concern or responsibility. But only when I hear the result that the ones who cheated got an A and I may get a B or B-, then I start to feel upset, and sometimes I will say to myself I should have cheated too. But at the end of the day, as I said, how am I going to learn if I cheat, and how am I going to know what my mistakes or weaknesses are if I cheat? 
I think I was changed a little by the experience. Sometimes I would consider cheating but at the same time, the penalty possibly getting kicked out of the program, I wouldn't want to cheat. Especially I'm paying double tuition fee because I'm [an] out-of-state student. So all of those things I have to keep on reminding myself that I'm coming this far and don't want to take the chance of ruining anything.

Nurse educators could use the information like you are obtaining and go around to the different programs and tell them what you learned. Telling the students that cheating is not acceptable, and it can also affect you when you are going into the work place. You may end up cheating in the workplace too, and this could be a reason for you to lose your job or your license. I would suggest going into schools and talk to the students.

This has influenced my nursing education in a way that I should study harder. The other thing is that what--it kind of influence me that sometimes cheating --people that cheat is kind of really a negative reflection back on the person who is cheating. People may think that if they are a cheater, you are a cheater too. I realized that it doesn't make sense for me to cheat. At the end of the day, you're going to get kicked out of the program if you get caught cheating. So I learned that I study by myself where I keep away from the students who I know are cheating and I go ask the professor for some help. I think that's the best way to go right now. But it isn't really affecting me because I understand that the students who do cheat at the end of the day, if you ask them about something they don't really understand it, they don't. The students are really cheating themselves.

In this school the students are focused on their studies. We have policies in place, we have to sign the academic integrity before we take exams. No one wants to get kicked out of the program for cheating. Everyone wants to get good grades. Now we help each other study, I met 
a girl and she was complaining about her grade, at the same time I did get in the 70's, so I said to this girl you fail I fail or if I get an A or a B to pass this course we both will, we will do it as a group. We are in the same clinical section and if I don't understand it you probably don't understand it so we can work with each other and help each other. That helped motivate her, now we are both doing well. At first she didn't understand that I was talking about studying together, she thought I meant to cheat. I think she misunderstood because of the culture, but I explained to her no its not cheating if we work in a group to prepare for the exam, cheating is when you copy off of someone during the test. So she said she understood and so far we are both doing good. We are going to tutoring and we are both doing really good. No cheating so far, LOL.

We also have to sign a sheet at the beginning of the exam and I think it influences the students not to cheat. Because everyone is thinking about that this is a private institution. The tuition is like 13-14,000 dollars. Why should I cheat just to get kicked out. If you work hard, you can reach your goal and if you fail, you can go back and try it again. You can have a second chance.

I just want to say if you could get more opportunities to go into schools like this, like I said before and stress to the students that there is no benefit to cheating, and you will only be cheating yourself, then maybe they would understand. Also that schools really need to enforce their policies. At this school they really enforce the integrity policy and if the school does that then it cuts down on the cheating.

\section{Reflection and Analysis}

Melissa's story demonstrates that she has an understanding of academic misconduct and indicates that she has never participated herself, but has witnessed cheating during an exam at 
her school. Melissa speaks about how this makes her feel, stating that "it is unfair because the person who is cheating may make better grades". She notes, that however, that at the end of the day, "she is the one who needs to know the material". Melissa discusses why she does not feel it is her place to report the incidents of cheating, stating that "the professors should be the ones who discover the problem and then address the problem". Melissa seems to understand that it is her responsibility to figure out how to do well in the program without cheating and that cheating is not worth the risk of being dismissed from the program. She also states that cheating is a "negative reflection back on the person who is cheating". Melissa discusses "the importance of the academic integrity policy and how it may be beneficial for the researcher to go around to different programs and speak about the issue of academic misconduct and its ramifications to students and future nurses".

As the inquirer I use the three commonplaces of temporality, sociality, and place. Temporality includes the thinking inward and outward, backward and forward about our interview. As I look inward I think about how may affect students as they continue with their education. If some students get away with cheating, it could lead students on the verge of failing to possibly see this as an option for themselves. Melissa speaks of the importance of being prepared to care for patients upon graduation, a real concern for nurse educators and facilities that provide care. Creating environments of trust is important for students and for practicing nurses as it may help decrease cheating and also promote reporting when someone does cheat. Melissa also speaks about the NCLEX and how students will ultimately have to pass to practice nursing.

The second common place, sociality, speaks about relationships. Melissa speaks about her classmates, especially her friend who is a student in her clinical section. Melissa and this 
student have formed a study group to support each other in the hopes of being successful. Melissa talks about how she also reaches out to her professors if she feels she needs help. All of these things speak to Melissa's sociality in reference to the three commonplaces. The third commonplace is place. The initial experience takes place within a school setting. Melissa vividly explains what happened during the experience of academic misconduct. Although she does not go into detail about what the room looked like, she is able to describe the students who were cheating and also how this made her feel.

\section{Three Levels of Analysis}

After reflecting upon Melissa's story I think about the three justifications: personal, practical, and social. For the first level of analysis, the inquirer situates himself/herself in the study. As the researcher if I situate myself in the study, I would feel angry and upset that students cheat to pass the course. I may also think about the kind of nurse they may become. The fact that students may be talking during an exam could also be distracting which may cause me not to do as well on the exam as I might have.

The second level of justification is the practical, how this experience will impact the researcher's professional practice. As I read Melissa's story and reflect upon it as a nurse educator, I need to be aware that there is a possibility that students are cheating on exams. After reading and reflecting, I also have to be attentive to students who may need assistance in their studies. As an educator I have office hours but many students do not take advantage of them. Melissa has formed a study group on her own and states she reaches out to her professor when needed, I may have to find a new approach to helping students realize the importance of seeking help. Melissa also talks about this researcher going around and sharing the information obtained 
and how it may affect the nursing students and also the nurses they may become. Sometimes we do not realize something until it is pointed out to us.

The third and last level is social justification. As the researcher I will take a step back and see how academic misconduct may affect students' education and the emotional well being. Do nurse educators create an atmosphere where the students feel safe to approach faculty members. Do students need extra emotional as well as educational support? Do we as faculty members know how to provide these services or how the students can receive them? These are questions I need to ask myself as a nurse educator so that we can prepare the best educated and emotionally stable graduates, who will be prepared for the clinical setting.

\section{Data Analysis}

In this study, the researcher conducted narrative analyses of five digitally recorded interview sessions of individual volunteer participants who witnessed academic misconduct during their associate degree nursing education. The sample included five women aged 21 to 47 years old who were enrolled in associate degree nursing programs during the time of the interview.

Narrative inquiry was used as the research methodology for this research study. The researcher read and re-read the transcripts while listening to the digital recordings of the interviews for accuracy. The researcher also kept a journal, which was referred to while analyzing the data for this study. Four themes emerged during the analysis. The researcher assigned the following titles to the themes that were identified: Theme \#1, Rules: Perception of rules unfulfilled, Theme \#2, Fear of getting caught while feeling pressure to succeed at all costs; Theme \#3, Solidarity: Treat others as I want to be treated and Theme \#4, Success or Failure: 
Cheating throughout the program; you may only be cheating yourself(see Tables 2.1,

\section{$2.2,2.3, .2 .4)$.}

Theme \#1: Rules-Perception of rules unfulfilled

Table 2.1

\begin{tabular}{|l|l|}
\hline \multicolumn{2}{|c|}{ Theme \#1: Rules: Perception of rules unfulfilled } \\
\hline $\begin{array}{l}\text { Narratives reflect participants' discussion of } \\
\text { their perception of how rules are not realized }\end{array}$ & Pseudonym \\
\hline $\begin{array}{l}\text { I just wish that whatever the rules they have, } \\
\text { they would just, like stick to it, and you know } \\
\text { do it. }\end{array}$ & Alicia \\
\hline $\begin{array}{l}\text { If the rule said you might be on probation if } \\
\text { caught cheating I want to see it. }\end{array}$ & Alicia \\
\hline $\begin{array}{l}\text { Sometimes they follow the rules and } \\
\text { sometimes they don't, like you can't leave the } \\
\text { room or you can't have a cell phone. }\end{array}$ & Alicia \\
\hline Strict rules; they don't always follow & Alicia \\
\hline $\begin{array}{l}\text { I reported someone cheating but I don't know if } \\
\text { they reported it. }\end{array}$ & Vanessa \\
\hline $\begin{array}{l}\text { There was a student who I know failed in } \\
\text { second and third semester and she was allowed } \\
\text { to repeat. So it's like, where is the rule, right? }\end{array}$ & Vanessa \\
\hline $\begin{array}{l}\text { Two students were caught cheating and I don't } \\
\text { know if they were penalized in a more private } \\
\text { way but they weren't kicked out of the } \\
\text { program. I feel a way to show everyone else } \\
\text { even though it is terrible for the person, they } \\
\text { should at least be on probation, but they won't } \\
\text { be put out of the program. }\end{array}$ & Rachel \\
\hline Did professor turn a blind eye to the cheating? & Eileen \\
\hline $\begin{array}{l}\text { Can't say if the professor was fair to all of us. } \\
\text { The person who cheated is in the program right } \\
\text { now. }\end{array}$ & Eileen \\
\hline
\end{tabular}

Five out of five participants in this study mention that they felt their program should follow the rules of the program more closely when someone is caught participating in academic misconduct. The participants also felt that faculty should follow the rules when someone is suspected of academic misconduct. 
Alicia (Participant 1) mentioned a few times during her interview how frustrated she was by the department not following the rules that were in place: "They have a lot of rules, stuff like that, but I don't feel like sometimes they follow it. Like, some silly rules like you can't leave the room or you can't have your cell phone but some students still use them. Alicia also says, "I just wish that whatever the rules were they would just follow them, if you [are]an unlucky one that gets caught, then I want to know if the rule said you should be on probation I want to see that. Rachel (Participant 3) states: "Two students were caught cheating and I don't know if they were penalized in a more private way but they weren't kicked out of the program, I feel a way to show everyone else even though it is terrible for the person, they should at least be on probation, but they won't be put out of the program."

Nursing education and nursing practice are guided by a code of ethics, first established in 1953. The code establishes a set of duties and obligations that the nurse must follow and use when providing care to patients (ANA, 2001, 2015). Nurses' primary responsibility is to the patient and providing safe and effective care. Nurses who participated in academic misconduct during their education, may not have the educational foundation necessary to provide this care (Jeffreys \& Stier, 1995, 1998, 2004). Nurses are expected to have personal integrity, which includes honesty; participating in academic misconduct would negate this provision. There is also a Nursing Student Code of Ethics that includes such provisions as receiving a quality education, which includes the powers of reasoning and judgment, and professionalism, which includes honesty, integrity, and responsibility (NSNA, 2009). A student who participates in academic misconduct is not following the provisions in either code of ethics. 


\section{Theme \#2: Fear of getting caught while feeling pressure to succeed at all costs}

Table 2.2

\section{Theme \#2 Fear of getting caught while feeling pressure to succeed at all costs.}

\begin{tabular}{|l|l|}
\hline $\begin{array}{l}\text { Narrative reflection: participants discuss their } \\
\text { feelings of pressure to succeed at all costs }\end{array}$ & Pseudonyms \\
\hline $\begin{array}{l}\text { I am always afraid of being caught but I don't } \\
\text { even think about it. }\end{array}$ & Alicia \\
\hline $\begin{array}{l}\text { A feeling of desperation, that no matter what I } \\
\text { need to pass. }\end{array}$ & Vanessa \\
\hline $\begin{array}{l}\text { I think students are afraid to get caught, but } \\
\text { they still might cheat. }\end{array}$ & Rachel \\
\hline $\begin{array}{l}\text { At the end of the day you may be kicked out of } \\
\text { the program if caught cheating. }\end{array}$ & Rachel \\
\hline $\begin{array}{l}\text { Having children, going back to school as an } \\
\text { adult, being away from the A\&P classes for so } \\
\text { long, other life issues, job and certain things } \\
\text { like that might force someone to cheat. }\end{array}$ & Eileen \\
\hline
\end{tabular}

Four out of the five participants mention that students may have a feeling of desperation, of having to pass at all costs. That the pressures of having to pass the course and outside commitments might push a student to participate in academic misconduct. Eileen (Participant 4) states, "yeah, definitely," when asked if outside commitments affect academic misconduct. Eileen (Participant 4) states, "You know, having children, going back to school as an adult, being away from the A\&P classes for so long, other life issues, job, certain things like that, you know, might force somebody to cheat." Alicia (Participant 1) states, "I am always afraid of being caught but I don't even think about it".

The ANA Code of Ethics plays a major role in this theme. Students who cheat because they are afraid to fail, break many of the provisions provided in the code (ANA, 2001, 2015). Nurses are supposed to put the safety and care of their patients at the forefront of their care. Participating in academic misconduct may decrease the knowledge the new nurse has and 
therefore affect the care provided to the patient. Integrity, honesty, and responsibility are all part of the Nursing Student's Code of Ethics and participation in academic misconduct goes against this code (NSNA, 2009).

Theme \#3: Solidarity: Treat others as I want to be treated

Table 2.3

\begin{tabular}{|c|c|}
\hline \multicolumn{2}{|c|}{ Theme \#3 Solidarity: Treat others as I want to be treated } \\
\hline $\begin{array}{l}\text { Narrative reflections: participants discuss } \\
\text { solidarity, interpersonal connections, and } \\
\text { community }\end{array}$ & Pseudonyms \\
\hline $\begin{array}{l}\text { Before I was in the nursing classes, I would } \\
\text { report someone cheating to my professor, but I } \\
\text { don't know why once I was in nursing like, } \\
\text { everybody wants to pass, and I want my } \\
\text { classmates to pass too, but sometimes you } \\
\text { know how they do it. }\end{array}$ & Alicia \\
\hline $\begin{array}{l}\text { I can't really explain why in, like nursing-wise, } \\
\text { it feels not the same to me, like, to report on } \\
\text { my classmates. I always think you know, they } \\
\text { can't graduate. }\end{array}$ & Alicia \\
\hline I am not reporting anyone. & Alicia \\
\hline $\begin{array}{l}\text { I think because nursing is a smaller group and I } \\
\text { kind of feel like everyone has their issues. } \\
\text { They have their struggles but everyone has the } \\
\text { same goal to pass the NCLEX and get a good } \\
\text { job. }\end{array}$ & Alicia \\
\hline $\begin{array}{l}\text { I reported that someone was cheating in class } \\
\text { but I did not give the name because I did not } \\
\text { want the person to get in trouble. }\end{array}$ & Vanessa \\
\hline $\begin{array}{l}\text { It bothered me I was telling everyone about it, } \\
\text { but I did not report it. }\end{array}$ & Rachel \\
\hline $\begin{array}{l}\text { I think this kind of thing could jeopardize their } \\
\text { whole nursing career. I wasn't prepared to } \\
\text { make that sacrifice for them. }\end{array}$ & Rachel \\
\hline $\begin{array}{l}\text { I feel like it's not my business to say } \\
\text { something, I am definitely not that student that } \\
\text { is going to tell the professor. }\end{array}$ & Eileen \\
\hline $\begin{array}{l}\text { I feel the professor should be the one to } \\
\text { discover the cheating I am a student and don't } \\
\text { feel it is my place to report on another student. }\end{array}$ & Melissa \\
\hline Now we help each other study. & Melissa \\
\hline
\end{tabular}


All five participants discussed not directly reporting their classmates or wanting to help their classmates once in the nursing program. One participant did email a faculty member about an incident but did not disclose the name of the student involved. The closeness of the students in the nursing program and not wanting to ruin a student's chance of graduating from the program, deter them from reporting students who participate in academic misconduct. Although they might report the incident they would not report the person. The participants also stated they wouldn't want someone to report them if they saw them participating in academic misconduct.

Alicia (Participant 1) states, "Before I was in the nursing classes, I would report someone cheating to my professor, but I don't know why once I was in nursing like, everybody wants to pass, and I want my classmates to pass too, but sometimes you know how they do it. I can't really explain why in, like nursing-wise, it feels not the same to me, like, to report on my classmates. I always think you know, they can’t graduate." Alicia also states, "I think because nursing is a smaller group and I kind of feel like everyone has their issues. They have their struggles but everyone has the same goal to pass the NCLEX and get a good job." Vanessa (participant 2) reported that someone was cheating in class but did not give the person's name because she did not want the person to get in trouble. Rachel (participant 3) states, "It bothered me. I was telling everyone about it, but I did not report it."

These quotes reveal a theme of solidarity-treat others as they want to be treated. Solidarity is defined as a unity or feeling of action especially among individuals with a common interest or mutual support within a group (Oxford Dictionary, n.d.). Once in the nursing program the students experience a sense of unity and the need to support one another to make it through the program. Nurses work with nurses and other healthcare practitioners, which may foster an environment of solidarity (https://www.nursing.upenn.edu/nhhc/american-nursing-an- 
introduction-to-the-past/). Today's' nursing organizations create a spirit of solidarity and action, evidenced by the students' refusal to report those responsible for cheating.

Theme \#4: Success or Failure: Cheating throughout the program; you may only be cheating yourself.

Table 2.4

\begin{tabular}{|c|c|}
\hline \multicolumn{2}{|c|}{$\begin{array}{l}\text { Theme \#4: Success or Failure: Cheating throughout the program; you may only be } \\
\text { cheating yourself }\end{array}$} \\
\hline $\begin{array}{l}\text { Narrative reflections: participants discuss } \\
\text { cheating throughout program while also } \\
\text { suggesting a lack of consequences }\end{array}$ & Pseudonyms \\
\hline $\begin{array}{l}\text { So even if they make it through the semester I } \\
\text { don't think they're going to make it through the } \\
\text { NCLEX }\end{array}$ & Alicia \\
\hline $\begin{array}{l}\text { So everyone is going to take the NCLEX, so as } \\
\text { long as they get the degree they can take the } \\
\text { NCLEX }\end{array}$ & Alicia \\
\hline $\begin{array}{l}\text { I never heard anyone say any student who } \\
\text { graduated from this program wasn't ready to } \\
\text { practice as a nurse. }\end{array}$ & Vanessa \\
\hline $\begin{array}{l}\text { That guy he is knowledgeable, he will prove } \\
\text { himself after graduation }\end{array}$ & Vanessa \\
\hline $\begin{array}{l}\text { I think they're going to mess up at some point } \\
\text { later on, on their own }\end{array}$ & Rachel \\
\hline $\begin{array}{l}\text { At some point you're going to fail something if } \\
\text { you've been cheating. }\end{array}$ & Eileen \\
\hline $\begin{array}{l}\text { So, right you can't cheat on the NCLEX. I } \\
\text { would say that could weed you out } \\
\text { immediately. }\end{array}$ & Eileen \\
\hline $\begin{array}{l}\text { Because cheating you are only cheating } \\
\text { yourself. }\end{array}$ & Melissa \\
\hline
\end{tabular}

All five participants spoke about how participation in academic misconduct will eventually catch up with the person who is cheating. All nursing graduates must pass the NCLEX to obtain a nursing license and practice as a registered nurse. Participation in academic misconduct during their nursing education may prevent a student from obtaining the necessary knowledge needed to be successful on the NCLEX exam (Jeffreys \& Stier, 1995, 1998, 2004). 
The NCLEX exam has one purpose, to determine if the applicant is safe to begin practice as an entry-level nurse. Nursing is regulated, and nurses, the second largest group of licensed professionals in the United States, must meet minimal qualifications and competencies for safe entry-level practice (https://www.ncsbn.org/index.htm). If students participate in academic misconduct during their nursing education, they risk not having the minimal knowledge necessary to pass the NCLEX.

The public has ranked nursing as the most ethical and honest profession in the country for 16 years (Gallup, 2017). This trust is based on the assumption that the nurse caring for a patient is a competent qualified professional who puts the patients' best interest and safety first. A license granted by a governmental entity provides this assurance to the public that the nurse caring for them has met these predetermined standards. The NCLEX exam is based on nursing knowledge obtained during nursing education and how it is applied in real-life situations. Students who cheated their way through a nursing program may not have the necessary knowledge to pass the exam and this helps protect the profession.

\section{The Composite Re-Story of the Story}

Data and exemplars gives the researcher an opportunity to consider a composite re-story that is conclusive and whole in what is learned. A final form or re-presentation of analyzing the data and in preparation for creating the re-story this researcher created a pastiche. From the experiences of my co-participants and my reflection on their stories as is appropriate in narrative inquiry a pastiche was written (Appendix E).

\section{Re-presentation}

It is the day of our second exam. We anxiously wait outside the classroom in the long drab hallway for the professor to come and let us into the room. The professor opens the doors 
and the students enter a large auditorium-like room with rows on each side and an aisle in the middle. Students from two different semesters are taking the exam in the one classroom at the same time. We are told that students from one semester will be in every other seat, with students from the other semester filling the other seats. I notice that in the back of the classroom a student is arguing with another student about a specific seat that he wants. I ask, myself, why would he want that seat, and why is he arguing with that girl? He doesn't even know her. But I pay it no mind and I find a seat and begin to prepare for the exam. Before the exam the professor tells us to shut off our cell phones and place them in our bags and place all bags and water bottles in the front of the classroom. The professor also tells us that we cannot have our watches because during the NCLEX, the only things we will have with us are scrap paper, pencils and glasses if needed.

Before we are able to begin the exam, we sign an academic integrity statement. Do the students in my class even know what they are signing, or are we blindly signing a paper so we can start the exam? The professor then tells us that we have one hour to complete the exam and that we can begin. While I am taking my exam I am seated between two students from the other semester. During the exam the two of them begin sharing their answers and I say, "What are you crazy"? They lower their voices but continue to share their answers with each other. I can't believe what is happening and I am having a very difficult time concentrating on my own exam.

I had heard that there might be some cheating going on in the school but to be caught in the middle of it, and that students were so brazen, I just couldn't believe it. The professor is standing in the front of the room so I guess she cannot see what the students are doing in the back or just doesn't make a big deal about it. I can hear a student in the front of the classroom 
asking for permission to leave the room and go to the bathroom. The professor says no, you cannot leave the testing area once the exam begins.

The exam is over and the professor collects the exams and Scantrons. The two semesters are then divided into two separate classrooms to review the exam. Once all of the exams and Scantrons are collected, the professor begins reviewing the exam. The professor puts the questions on the projector screen so that students can see them. While we are reviewing the exam, I notice that a student has her cell phone and taking pictures of the exam, even though we were told no cell phones were allowed. All the students know that we will see some of the same questions on the final exam so if we can get as many questions as possible, we will have a good idea of what questions will be on the final. At first I am like, what are you doing, but then I say to the girls, "hey you better share those questions with me." Why should they get a leg up on the final exam? I don't want to cheat but I have the desire to have the information so I can do well on the final. After reviewing the exam we are dismissed and all file out into the long hallway. In the hallway I hear students discussing the male student who was fighting for a seat. My classmates were saying he wanted that seat because you can see diagonally onto someone else's paper. Maeve, who is the smartest student in the class, was sitting diagonally in front of the seat he was trying to get. This way he could see her exam. When we got the grades back it was confirmed because he got the second highest grade in the class. My friend Maeve always does well, she always makes the highest grade. The other student, who had previously failed this course, received the second highest grade. I kept thinking to myself, what should I do? I know about three incidences of cheating that took place during this exam. Should I keep it to myself or should I share it with a faculty member? 
I decided to email the faculty member who taught our course and the one who taught the other semester course--which took the exam with us that day--and let them know what was going on. They could take it from there. I emailed each faculty member about the incidences but did not give any names because I do not want to be the one who ruins someone's chance of becoming a nurse. I figure they will have to take the NCLEX exam like the rest of us and if they don't know the material they will not pass.

I also did not report the students who took pictures of the exam because I am hoping that they will share that information with me so that I have those questions for the final. I often think to myself, we have so many rules in the nursing program, but the faculty don't always stick to them. They say no cell phones, but somehow students still have their cell phones and are able to use them to get the questions. No talking during an exam and yet those two students sitting on each side of me were sharing answers throughout the exam, and the gentleman with the seat knew that he would be able to see the other student's exam and get the answers. You can only have two failures, yet we see so many classmates that we know with at least two failures still in the program. This makes it very frustrating as a student. The faculty members thanked me politely but since I did not name anyone in particular they couldn't do anything. They did assign seats during the next exam to try and prevent the same thing from happening again and we no longer review our exams afterwards.

Although the students know these events all occurred, it appears that nothing has been done about it. The rules put in place to protect the integrity of the exam and the program have not been followed. The students are still seen on campus and act as if nothing has happened. This makes me feel angry that I know these students have broken the rules, yet they are still allowed to be in the program. At the end of the semester we also heard that there were a few 
students who failed a course for the second time. This is supposed to mean dismissal from the

program. Yet, again, we see them in the hallway attending class. As students we struggle with all of these issues, but figure in the long run who am I to end someone's dream of becoming a nurse and having a career. I figure the NCLEX will be the reason they can or cannot become a nurse. The nursing students seem to want to stick together and protect one another. I do worry that cheating on exams may be a negative reflection on the nursing profession. If people think that nursing students cheat on exams, will they worry that the nurses taking care of them may have cheated also. At the end of the day, I know that I did my best and I hope that my classmates did their best too.

\section{Summary of Findings}

This section provided the findings of the narrative inquiry on associate degree nursing students and academic misconduct. This researcher identified four themes from the experiences of the participants: Theme \# 1, Rules: Perception of rules unfulfilled; Theme \#2, Fear of failing greater than fear of getting caught; Theme \#3, Solidarity: Treat others as I want to be treated; and Theme \# 4, Success or Failure: Cheating through the program; you may only be cheating yourself. Re-storying of the narratives about academic misconduct was also transformational as it "unfolded" the participants' stories, which allowed for new meaning making and revealed the nuances in the participants' stories. These nuances revealed during the participants' stories of witnessing academic misconduct had a profound effect on the participants and made them think about their feelings towards academic misconduct, the students that participated in academic misconduct, and how the phenomenon may affect nursing as a profession. 


\section{Chapter Summary}

This chapter presented the demographic data and analyzed the experience of five voluntary research participants examining their stories of academic misconduct during their nursing education. The research sample included participants who had witnessed academic misconduct during their associate degree nursing education. The research participants' experiences were transcribed and review of the transcripts was conducted to identify common resonant themes. The researcher uncovered four recurrent themes while reading and rereading transcripts and listening to the participants audio recordings and referring to the reflective journal kept during the process. These themes were integrated in the discussion and implications for research, and interventions are highlighted in the next chapter of this study. This research study told the stories of AD nursing students and their experiences with academic misconduct. 


\section{Chapter 6}

\section{Discussion}

The purpose of this study using narrative inquiry was to gain a deeper understanding of AD nursing students' stories of their experience of academic misconduct, either through participation in or witnessing academic misconduct during their nursing education. This study addressed the research question: What are the stories of Associate Degree nursing students with academic misconduct experiences during their nursing education? This study examined the stories of five volunteer research participants, focusing on their experience of academic misconduct during their associate degree nursing education. The emerging four themes revealed in their stories provide additional information which may help nurse educators and others better understand how associate degree nursing students make sense of academic misconduct. While this study expanded the story on the topic of academic misconduct it also presented limitations that may suggest further areas of additional research.

\section{Addressing Academic Misconduct}

The phenomenon of academic misconduct is important to study because the educational goal of nursing education is to prepare students to care for patients in the clinical setting who are competent, safe, and honest (Bellack, 2004). Gaberson (1997) identified the reality that nursing students may be participating in academic misconduct during their education, which might jeopardize their future nursing practice, patient outcomes, and the profession of nursing itself. The effects of academic misconduct on patients, other students, the nursing education program, and the profession were are also discussed. Like Gaberson, the findings of my study included participants' concerns about the consequences of academic misconduct as expressed in their stories (see Table 2.4). 
Given the documented prevalence of misconduct, Jeffreys and Stier $(1995,1998,2004)$ studied ways to decrease, if not eliminate such behavior, especially among nursing students. For example, Jeffreys and Stier offered options to deter academic misconduct in the nursing education field, including providing a clear definition of academic misconduct and giving concrete examples that students will understand; securing the integrity of exams; using large classrooms so the students can be spread out and away from each other; and instituting an honor code for both faculty and students. Nursing students who have successfully passed their nursing program but have participated in academic misconduct to get there may not have the educational foundation to practice safely once they enter the clinical setting, which may tarnish the reputation of their school, the profession of nursing, and the employing institution, in addition to harming the patients they are intended to serve. The evidence-based strategies are employed in schools of nursing to limit academic misconduct; however, the findings suggest that students are at best confused and perceive that the "rules" are not applied uniformly (see Table 2.1).

\section{Self Reflection of the Experience of the Researcher}

As a professional registered nurse and nurse educator, this research is of concern to me as faculty. My experiences administering exams and working with students in institutions of higher education have led to my interest in studying the phenomenon of academic misconduct. This phenomenon has become a passion of mine. Therefore; to gain insight on this topic from the perspective of the students, I decided to conduct this research study using the qualitative method of narrative inquiry. While interpreting the data, audio recordings, and reflective journal, it became clearer to me as the researcher how this reflection affected me as a professional registered nurse and nurse educator. 
As the researcher I imagined the inquiry space to include AD nursing students currently enrolled in a nursing program. I also thought about all AD nursing students, those students who participated in my study and those who may have been affected by academic misconduct but who felt uncomfortable or fearful to speak with me. I also thought about the nursing instructors/professors who teach in nursing programs and the burden academic misconduct or the possibility of misconduct, puts on them. Classroom management during an exam and creating new questions for every exam to deter cheating or possible cheating are time consuming and stressful. I also thought about the patients for whom these nurses may be providing care. Nursing students who participate in academic misconduct during their education may participate in this behavior while in practice (Gaberson, 1997; Klainberg et al., 2013; McCrink, 2010). They may also lack the educational foundation to properly care for patients under their care (Jeffreys \& Stier, 1995, 1998, 2004). I imagined how the academic setting and its narrative may influence the stories told by participants and how this could affect myself as the researcher and nurse educator.

\section{Summary of the Study}

Academic misconduct as a phenomenon is understood and identified in research literature as: “intentional participation in deceptive practices regarding one's academic work or work of another" (Gaberson, 1997, p. 14). Prescott (1989) described academic misconduct as "fraudulent behavior involving some form of deception whereby one's work or the work of others is misrepresented" (p. 284). The purpose of this research study was to gain a deeper understanding of AD nursing students' experiences with academic misconduct, which may include participation in or witnessing academic misconduct during their nursing education process and give voice to their storied experience. The primary research question guiding this study was: "What are the 
stories of Associate Degree nursing students' experiences with academic misconduct during their nursing education?" This study examined the stories of five female volunteer research participants, focusing on their experiences of academic misconduct while in an AD nursing program using a qualitative methodology; specifically, narrative inquiry.

Four themes emerged from the data and each can be considered within the context of the research literature and the ANA Code of Ethics (2001, 2015). The first theme addressed student perceptions about the rules made by faculty and/or program related to testing. The literature includes studies and recommendations about strategies to promote academic integrity and deter academic misconduct (Jeffreys \& Stier,1995,1998, 2004; McCabe, 2009). The participants' concerns suggest students may perceive multiple standards and may experience feelings of vulnerability when "rules" aren't followed. Adherence to the ANA Code of Ethics which protects the integrity of the profession, and supports the covenant between the profession of nursing and society provides a set of "rules" for nursing professionals to follow. It also provides nurse educators with a defined educational requirement for entry into practice. The ANA Code of Ethics establishes a set of duties and obligations that the nurse must follow and use when providing care to patients $(2001,2015)$. Nurses' primary responsibility is to the patient and providing safe and effective care.

The second theme addressed the fear of getting caught and feeling pressure to succeed in their program. The pressure to succeed was linked to academic misconduct by early researchers who studied non-nursing college students (Drake, 1941; Parr,1936). More current researchers who related academic misconduct to the competitive nature of today's society and the emphasis on personal success (Balik et al.,2010). Similarly in nursing, Hilbert (1987), McCabe (2009), and Wideman (2011) examined forms of academic misconduct in baccalaureate nursing students 
and found the most common reason for cheating was attributed to the pressure for academic success. Nursing students and faculty are under great pressure to succeed. Faculty need to provide exams that will measure a student's knowledge while preparing them for the NCLEX exam. While students feel great pressure to perform well on the exams to pass their courses and complete their nursing program (NLN, 2010).

The third theme addressed solidarity; a desire not to negatively impact another student's chances for success. Solidarity is defined as a unity or feeling of action especially among individuals with a common interest or mutual support within a group (Oxford Dictionary, n.d.). The fact that participants didn't report classmates while in the nursing program underscores the feeling of solidarity of students in the nursing program. Students wouldn't want others to report them if they were in the same position so they don't want to report their fellow students. Once in the nursing program the students experience a sense of unity and the need to support one another to make it through the program. Being in this nursing community provides students with a sense of community and the desire to protect others from losing the opportunity to have a career. Students who form relationships during their nursing education develop bonds that lead to solidarity. The ability to form relationships in the educational setting provides the groundwork necessary to develop and foster relationships once in professional practice. Provision eight in the ANA Code of Ethics states the nurse collaborates with other health professionals and the public to protect human rights, promote health diplomacy, and reduce health disparities this practice can lead to a sense of solidarity (ANA, 2001, 2015).

The final theme addressed the important realization that in cheating one may only be cheating themselves. Nurses who participated in academic misconduct during their education, may not have the educational foundation necessary to provide this care (Jeffreys \& Stier, 
1995,1998, 2004). Students need to pass the NCLEX to become a registered nurse after they graduate which the profession has deemed as determining that professional nurses who pass NCLEX have the educational foundation for professional nursing practice. Some nursing students may pass the NCLEX exam, even though they may have cheated during their nursing education. For those nursing students who cheated and passed, the question is, do they really, truly, deeply have the necessary knowledge to provide care for patients once they graduate, pass the NCLEX and begin working (Jeffreys \& Stier, 1994,1998, 2004)? While this study expanded the story of associate degree nursing students and academic misconduct it also raised many questions for further research.

\section{Limitations}

The primary limitation is transferability. As only students who witnessed academic misconduct participated in the study, transferability may be limited to associate degree nursing students who witnessed academic misconduct during their studies. Only one participant indicated the possibility of participation in academic misconduct; however, the participant's story did not indicate a recognition of the incident as academic misconduct. Clearly, discussing actual engagement in academic misconduct is a sensitive topic for students currently enrolled in an academic program.

Clandinin and Connelly (2000) address limitations or persistent concerns inherent in the narrative inquiry method and suggest that the question of "factuality and truthfulness" (p. 179) may arise as it relates to the story and the researcher's writing. For example in this study, one might wonder about the degree of engagement of academic misconduct or witnessing. Regardless of engagement or witnessing, the underlying assumptions of the narrative inquiry method lies in the participant-researcher relationship and the development of trust, as well as the 
researcher's role to listen, hear, and understand each participant's story (Clandinin, 2006).

Furthermore, the method calls for the researcher to think narratively, which includes spending time with the data to create a re-representation of each participant's experiences to help gain a better understanding of the issue (Connelly \& Clandinin, 2006). Ultimately, the telling of the story and retelling of the stories as a whole help to "capture personal experiences that are difficult to describe in facts and figures (Haydon \& van der Riet, 2014, p. 198)".

\section{Recommendations}

The findings and themes that emerged in this study need to be considered within the limitations of qualitative research in general and specifically narrative inquiry. As academic misconduct occurs in higher education in general, the assumption can be made that it also happens in nursing education when the success for academic success is paramount (McCabe, 2009). Nurse faculty and educators need to protect the integrity of the education their students receive and the nursing profession itself by trying to decrease and possibly eliminate academic misconduct from nursing education and nursing practice. The participants' stories revealed important topics that need to be considered in nursing education.

\section{Education}

Nursing faculty need to be aware that students come into the academic setting with different levels of moral development and role models for ethical behavior. Faculty members should be role models for their students to help them learn the professional behaviors necessary to be successful as professional registered nurses. The goal of nursing education is to prepare students as safe, competent, and honest (Bellack, 2004). Participants spoke about the importance 
of following the rules implemented in a department and what action takes place when there is an issue of academic misconduct.

Based on the literature and the researcher's reflection the following recommendations could be put in place. Educators may implement courses on nursing ethics and academic misconduct. It appears that some students do not have a good understanding of what academic misconduct is, and providing them with a better understanding could be a first step. Melissa (participant 5) suggested that this researcher should go around to different nursing programs and discuss the findings of this study to increase students' awareness. Students should feel that they can trust their faculty in both the academic setting and clinical setting. This trusting atmosphere may allow students to feel comfortable enough to report mistakes without fear of retribution. Implementation of an academic integrity policy may allow students the ability to understand the importance of academic honesty and its relationship to the expectations of how a professional nurse will practice (Gaberson, 1997).

\section{Practice}

Although my study did not address practice, the participants spoke about the potential impact of cheating on future practice (see table 2.4). Participant's concerns are evident in the literature, which suggest that if students participate in academic misconduct during their nursing education there is a good chance they may participate in misconduct in practice (Gaberson, 1997; Hilbert, 1985,1987; Klainberg et al., 2013McCrink, 2010). Nurse faculty may wish to engage in conversations with clinical practice colleagues to discuss and strategize about prevention of acts of misconduct or breeches of the ANA Code of Ethics. 


\section{Future Research}

Narrative Inquiry was the qualitative research method used for this study. The findings of this study provide a keen sense of value when using narratives and narrative inquiry. Further insight into the phenomenon may have been revealed if the researcher were able to recruit participants who actually participated in academic misconduct. Although recruiting participants who clearly identify as having engaged in academic misconduct may be difficult, it would be optimal for future research. In addition, a methodological variation might also prove helpful. For example, using a mixed-method approach, which would include a survey, would further expand the understanding of the phenomenon. Adding quantitative data will inform the findings of the narratives and provide further insight into the phenomenon.

Other avenues for future research may focus on participants who are in a different period of their education or career trajectory. For example, new graduate nurses and practicing nurses to gain some insight about cheating, NCLEX performance, and actual nursing practice. Another group that may be useful to hear from is nursing faculty members and their experiences with academic misconduct. It is important to understand faculty's experiences with students' cheating and their perception of the effects of students' cheating. Another potential study could be designed to interview faculty who have reported misconduct and their experience of reporting misconduct and the consequences of such reports.

\section{Conclusion}

The purpose of this study using narrative inquiry was to gain a deeper understanding of AD nursing students' stories of their experience of academic misconduct, either through participation in or witnessing academic misconduct during their nursing education. This research succeeded in giving a voice to those students who witnessed academic misconduct 
during their nursing education. Narrative inquiry as a method often gives voice to those not normally heard from and allows participants to make sense of the experience. This study adds a unique perspective within the nursing literature as most previous studies on academic misconduct were quantitative with baccalaureate nursing students as the subject. This qualitative study allowed participants to use their own words and stories to reveal how they understand the experience of academic misconduct, thus offering insight into the topic of academic misconduct in associate degree nursing students. 


\section{References}

ABC News. (2010). Columbia University valedictorian plagiarizes Patton Oswalt. Retrieved from http://abcnews.go.com/Technology/patton-oswalt-plagiarized-comedian-bustscolumbia-university-valedictorian/story?id=10740791

American Nurses Association (ANA). (2001). Code of ethics for nurses with interpretive statements. Silver Spring, MD: ANA.

American Nurses Association (ANA). (2015). Code of ethics for nurses with interpretive statements. Silver Spring, MD: ANA.

Arhin, A. (2009). A pilot study of nursing students' perceptions of academic dishonesty: A Generation Y perspective. ABNF Journal, 20(1), 17-21.

Arhin, A., \& Jones, K. (2009). A multidiscipline exploration of college students' perception of academic dishonesty: Are nursing students different from other college students? Nurse Education Today, 29, 710-714.

Bailey, P. (2001). Academic misconduct: Responses from deans and nurse educators. Journal of Nursing Education, 40(3), 124-131.

Balik, C., Sharon, C., Kelishek, S., \& Tabak, N. (2010). Attitudes towards academic cheating during nursing studies. Medicine \& Law, 29(4), 547-563.

Baxter, P. E., \& Boblin, S. L. (2007). The moral development of baccalaureate nursing students: Understanding ethical behavior in classroom and clinical settings. Journal of Nursing Education, 46, 20-27.

Bell, J. S. (2002). Narrative inquiry: More than just telling stories. TESOL Quarterly, 36, 207213.

Bellack, J. (2004). Why plagiarism matters. Journal of Nursing Education, 43(12), 527-528. 
Bowers, W.J.(1964). Students dishonesty and its control in college: New York, NY: Bureau of Applied Social Research, Columbia University.

Burns, N. \& Grove, S. (2013). The practice of nursing research ( $7^{\text {th }}$ ed.). St. Louis, MO: Elsevier.

Callahan, D. (2004). The cheating culture: Why more Americans are doing more to get ahead Orlando, FL: Harcourt.

Clandinin, D. J. (2006). Narrative inquiry: A methodology for studying lived experience. Research Studies in Music Education, 27(1), 44-54.

Clandinin, D. J. (2013). Engaging in narrative inquiry. Walnut Creek, CA: Left Coast Press.

Clandinin, D.J. \& Connelly, F. M. (1994). Personal experience methods. In N.K. Denzin and Y. Lincoln (Eds)., Handbook of qualitative research. Thousand Oaks, CA.: Sage.

Clandinin, D. J., \& Connelly, F. M. (1998). Stories to live by: Narrative understandings of school reform. Curriculum inquiry, 28(2), 149-164.

Clandinin, D. J., \& Connelly, F. M. (2000). Narrative inquiry: Experience and story in qualitative research. San Francisco, CA: Jossey-Bass.

Clandinin, D. J., \& Huber, J. (2010). Narrative Inquiry, In B. Teoksessa, E. McGaw, E. Baker, \& P.P. Peterson, (Eds.), International encyclopedia of education, (3rd ed., pp. 436-441). New York, NY: Elsevier.

Clandinin, D.J., Pushor, D., \& Orr, A.M. (2007). Navigating sites for narrative inquiry. Journal of Teacher Education, 58(1),21-35. 
Clandinin, D. J., \& Rosiek, J. (2007). Mapping a landscape of narrative inquiry: Borderland spaces and tensions. In D. J. Clandinin (Ed.), Handbook of narrative inquiry: Mapping a methodology (pp. 35-75). Thousand Oaks, CA: Sage Publications.

Connelly, F. M., \& Clandinin, D. J. (1990). Stories of experience and narrative inquiry. Educational Researcher, 19(5), 2-14.

Connelly, F. M., \& Clandinin, D. J. (2006). Narrative inquiry. In J. L. Green, G. Camilli, P. B. Elmore, A. Skukauskaite, \& Grace (Eds.), Handbook of complementary methods in education research (pp. 477-487). Washington, DC: Lawrence Erlbaum Associates.

Creswell, J. W. (2013). Qualitative inquiry and research design: Choosing among five approaches (3rd ed.). Thousand Oaks, CA: Sage.

Crittenden, V. L., Hanna, R. C., \& Peterson, R. A. (2009). Business students' attitudes toward unethical behavior: A multi-country comparison. Marketing Letters, 20(1), 1-14.

Daniel, L. G., Adams, B. N., \& Smith, N. M. (1994). Academic misconduct among nursing students: A multivariate investigation. Journal of Professional Nursing, 10(5), 278-288.

de Raeve, L. D. (2002). Trust and trustworthiness in nurse-patient relationships. Nursing Philosophy, 3, 152-162. doi:10.1046/j.1466-769X.2002.00090.x

Dewey, J. (1938). Experience and education. New York, NY: Collier Books.

Dewey, J. (1997). Experience and education (New York, Touchstone). (Original work published 1938.)

Drake, C. A. (1941). Why students cheat. The Journal of Higher Education, 12(8), 418-420. http://doi.org/10.2307/1976003 
Fontana, J. S. (2009). Nursing faculty experiences of students' academic dishonesty. Journal of Nursing Education, 48(4), 181-185. Retrieved from http://search.proquest.com/docview 203911988?accountid=8204

Gaberson, K. B. (1997, July). Academic dishonesty among nursing students. Nursing Forum,32(3), 14-20.

Gallup (2017). Americans rate nurses highest on honesty, ethical standards. Retrieved from: https://news.gallup.com/poll/224639/nurses-keep-healthy-lead-honest-ethicalprofession.aspx

Green, B. (2013). Narrative inquiry and nursing research. Qualitative Research Journal, 13(1), $62-71$.

Haydon, G., \& van der Riet, P. D. (2014). A narrative inquiry: How do nurses respond to patients' use of humour? Contemporary Nurse: A Journal for the Australian Nursing Profession, 46(2), $\quad$ 197-205. doi:10.5172/conu.2014.46.2.197

Hilbert, G. A. (1985). Involvement of nursing students in unethical classroom and clinical behaviors. Journal of Professional Nursing, 1(4), 230-234.

Hilbert, G. A. (1987). Academic fraud: Prevalence, practices, and reasons. Journal of Professional Nursing, 3(1), 39-45.

Hilbert, G. A. (1988). Moral development and unethical behavior among nursing students. Journal of Professional Nursing, 4(3), 163-167.

International Center of Academic Integrity (1999). The fundamental values of academic integrity. Retrieved from: http://www.academicintegrity.ort/icai/assets/FVProject.pdf.

International Center of Academic Integrity (2013). The fundamental values of academic integrity. Retrieved from: http://www.academicintegrity.org/icai/resources-2.php. 
Jeffreys, M. R., \& Stier, L.A. (1995). SPEAKING against student academic dishonesty: A communication model for nurse educators. Journal of Nursing Education, 34(7), 297304. Retrieved from http://search.proquest.com/docview/1026709094?accountid=8204

Jeffreys, M. R., \& Stier, L. A. (1998). Student academic dishonesty. Imprint, 45(3), 48-49.

Jeffreys, M.R. \& Stier, L. A. (2004). Student academic dishonesty. In M. Oermann, \& K. Heinrich, (Eds.), Annual Review of Nursing Education (Vol. 2, pp. 255-281). New York, N. Y. : Springer Publishing Company.

Jensen, L. A., Arnett, J. J., Feldman, S. S., \& Cauffman, E. (2002). It's wrong, but everybody does it: Academic dishonesty among high school and college students. Contemporary Educational Psychology, 27(2), 209-228.

Josselson, R. (2006). Narrative research and the challenge of accumulating knowledge. Narrative Inquiry, 16(1), 3-10.

Kavilanz, P. (2018, April 30). Nursing schools are rejecting thousands of applicants -- in the middle of a nursing shortage. Retrieved from https://money.cnn.com/2018/04/30/news/economy/nursing-school-rejections/index.html

Keçeci, A., Bulduk, S., Oruç, D., \& Çelik, S. (2011). Academic dishonesty among nursing students: A descriptive study. Nursing Ethics, 18(5), 725-733.

Kim, J. H. (2016). Understanding narrative inquiry: The crafting and analysis of stories as research. Thousand Oaks, CA: Sage.

Kirkpatrick, H., \& Byrne, C. (2009). A narrative inquiry: Moving on from homelessness for individuals with a major mental illness. Journal of Psychiatric and Mental Health Nursing, 16, 68-75. 
Klainberg, M. B., McCrink, A., Eckardt, P., Schecter, R., Bongiorno, A., \& Sedhom, L. (2013). Perspectives on academic misconduct: Implications for education and practice. The Journal of the New York State Nurses' Association, 44(1), 11-21.

Klocko, M. N. (2014). Academic dishonesty in schools of nursing: A literature review. Journal of Nursing Education, 53(3), 121-125. doi:10.3928/01484834-20140205-01

Kohlberg, L. (1976). Moral stages and moralization: The cognitive-development approach, in Licona, T. (ed): Moral Development and Behavior: Theory, Research, and Social Issues. New York, Holt, Rinehart \& Wilson.

Kolanko, K. M., Clark, C., Heinrich, K. T., Olive, D., Serembus, J. F., \& Sifford, K.S. (2006). Academic dishonesty, bullying, incivility, and violence: Difficult challenges facing nurse educators. Nursing Education Perspectives, 27(1), 34-43.

Krueger, L. M. (2013). Academic dishonesty among associate degree nursing students (Order No. 3564503). Available from ProQuest Dissertations \& Theses Global. (1409549628). Retrieved from http://search.proquest.com.libproxy.adelphi.edu: 2048 /docview / 1409549628 ?accountid $=8204$

Krueger, L. (2014). Academic dishonesty among nursing students. Journal of Nursing Education, 53(2), 77-87.

La Duke, R. D. (2013). Academic dishonesty today, unethical practices tomorrow? Journal of Professional Nursing, 29(6), 402-406.

Langone, M. (2007). Promoting integrity among nursing students. Journal of Nursing Education, 46(1), 45-47. 
Law, B. Y. S., \& Chan, E. A. (2015). The experience of learning to speak up: A narrative inquiry on newly graduated registered nurses. Journal of Clinical Nursing, 24(13-14), 18371848.

Lin, C. H. S., \& Wen, L. Y. M. (2007). Academic dishonesty in higher education-A nationwide study in Taiwan. Higher Education, 54(1), 85-97.

Lincoln, Y. S., \& Guba, E.G. (1985). Naturalistic inquiry. Beverley Hills, CA: Sage.

Lindsay, G. M. (2006). Constructing a nursing identity: Reflecting on and reconstructing experience. Reflective Practice, 7(1), 59-72. doi: 10.1080/14623940500489732

Lindsay, G. M., \& Schwind, J. K. (2016). Narrative inquiry experience matters. Canadian Journal of Nursing Research, 48(1), 14-20. 0844562116652230.

Mathews, C. O. (1932). "The honor system." Journal of Higher Education, $3(8), 411-415$.

McCabe, D.L.(1997). Classroom cheating among natural science and engineering majors. Science \& Engineering Ethics, 3:433-445.

McCabe, D. (2009). Academic dishonesty in nursing schools: An empirical investigation. Journal of Nursing Education, 48(11), 614-623. doi:10.3928/01484834-20090716-07

McCabe, D. L., Butterfield, K. D., \& Treviño, L. K. (2006). Academic dishonesty in graduate business programs: Prevalence, causes, and proposed action. Academy of Management Learning and Education, 5(3), 294-305.

McCabe, D.L., \& Treviño, L. K. (1993). Academic dishonesty, honor codes and other contextual influences. Journal of Higher Education,64,520-538. 
McCabe, D. L., \& Treviño, L. K. (1996). What we know about cheating in college longitudinal trends and recent developments. Change: The Magazine of Higher-Learning, 28(1), 28 33.

McCabe, D. L., Treviño, L. K., \& Butterfield, K. D. (2001). Cheating in academic institutions: A decade of research. Ethics and Behavior, 11(3), 219-232.

McCabe, D. L., Treviño, L. K., \& Butterfield, K. D. (2002). Honor codes and other contextual influences on academic integrity: a replication and extension to modified honor code settings. Research in Higher Education, 43(3), 357.

McCrink, A. (2010). Academic misconduct in nursing students: Behaviors, attitudes, rationalizations, and cultural identity. Journal of Nursing Education, 49(11), 653-659. doi:http://dx.doi.org/10.3928/01484834-20100831-03

Metersky, K., \& Schwind, J. (2015). Interprofessional care: Patient experience stories. The International Journal of Person Centered Medicine, 5(2),78-87.

Munhall, P. L. (2012). Nursing research: A qualitative perspective (5th ed.). Sudbury, MA: Jones \& Bartlett Learning.

Naghdipour, B., \& Emeagwali, O. L. (2013). Students' justifications for academic dishonesty: Call for action. Procedia Social and Behavioral Sciences, 83, 26-265.

National Council of State Boards of Nursing, Inc. [NCSBN], (2016). NCLEX® Results Page. Number of Candidates Taking NCLEX-RN® Examination and Percent Passing, 2015, by Type of Candidate. Retrieved from: https://ncsbn.org/16_2015_NCLEXExamStats_vol68.pdf 
National League of Nursing (NLN). (2012). Ethical principles for nursing education. Retrieved from: http://www.nln.org/docs/default-source/default-document-library/ethicalprinciples-for-nursing-education-final-final-010312.pdf?sfvrsn=2

National League for Nursing, (NLN). (2014). Annual survey of schools of nursing. Retrieved from: http://www.nln.org/docs/default-source/newsroom/nursing-education National League for Nursing, (NLN) (2010). High stakes testing. Retrieve https://ww1.prweb.com/prfiles/2010/12/13/130574/HighStakesTestingRandD.pdfd from National Student Nurses Association, (NSNA). (2009). Code of ethics: Part II code of academic and clinical conduct and interpretive statements. Retrieved from: www.nsna.org/Portals/0/Skins/NSNA/pdf/NSNA_CoC_Academic_Clinical_Inter p_Statements.pdf.

Nonis, S. A., \& Swift, C. O. (1998). Deterring cheating behavior in the marketing classroom: An analysis of the effects of demographics, attitudes, and in-class deterrent strategies. Journal of Marketing Education, 20(3), 188-199.

Nonis, S., \& Swift, C. O. (2001). An examination of the relationship between academic dishonesty and workplace dishonesty: A multicampus investigation. Journal of Education for Business, 77(2), 69-77.

Ollerenshaw, J. A., \& Creswell, J. W. (2002). Narrative research: A comparison of two restorying data analysis approaches. Qualitative Inquiry, 8(3), 329-347.

Oran, N. T., Can, H. Ö., Şenol, S., \& Hadımlı, A. P. (2015). Academic dishonesty among health science school students. Nursing Ethics,0969733015583929, 1-15. 
Palese, A., Petean, M., \& Cerne, D. (2014). Unexpected deaths in medical wards during night shifts: A narrative analysis of nursing experiences. Journal of clinical nursing, 23(17-18), 2599-2608.

Parr, F. W. (1936). The problem of student honesty. The Journal of Higher Education, 7(6), 318 326.

Polit, D., \& Tatano-Beck, C. (2017). Nursing research: Principles and methods. Philadelphia, PA: Lippincott, Williams \& Wilkins.

Prescott, P. A. (1989). Academic misconduct: Considerations for educational administrators. Journal of Professional Nursing, 5(5)283-287.

Riessman, C. K. (2006). Narrative analysis. In V. Jupp (Ed.), The Sage dictionary of social research methods (pp. 186-189). London, UK: Sage.

Riessman, C. (2008). Narrative method for the human sciences. London, UK: Sage.

Roberts, E. (1997). Ethical issues. Academic misconduct in schools of nursing. Nursing Connections, 10(3), 28-36.

Sandelowski, M. (1991). Telling stories: Narrative approaches in qualitative research. IMAGE: Journal of Nursing Scholarship, 23, 161-166.

Schwind, J. K. (2003). Reflective process of the study of illness stories as experienced by three nurse teachers. Reflective Practice, 4(1), 19-12. doi:10.1080/1462394032000053521.

Silverman, D. (2006). Interpreting qualitative data: Methods for analyzing talk, text and interaction. London, UK: Sage.

Solidarity. (n.d.). In Oxford Dictionary online retrieved from https://en.oxforddictionaries.com/definition/solidarity. 
Tanner, C. A. (2004). Moral decline or pragmatic decision making? Cheating and plagiarism in perspective. Journal of Nursing Education, 43(7), 291-292.

Tippitt, M., Ard, N., Kline, J., Tilghman, J., Chamberlain, B., \& Meagher, P. (2009). Creating environments that foster academic integrity. Nursing Education Perspectives, 30(4), 239244.

University of Pennsylvania School of Nursing. American nursing: an introduction to the past. Retrieved from https://www.nursing.upenn.edu/nhhc/american-nursing-an-introductionto-the-past/

Vito, K. O. (1983). Moral development considerations in nursing curricula. The Journal of Nursing Education, 22(3), 108.

Wideman, M. (2011). Caring or collusion? Academic dishonesty in a school of nursing. Canadian Journal of Higher Education, 41(2), 28-43.

Woith, W., Jenkins, S. D., \& Kerber, C. (2012, October). Perceptions of academic integrity among nursing students. Nursing Forum, 47(4), 253-259. 


\section{Appendix A}

Flyer

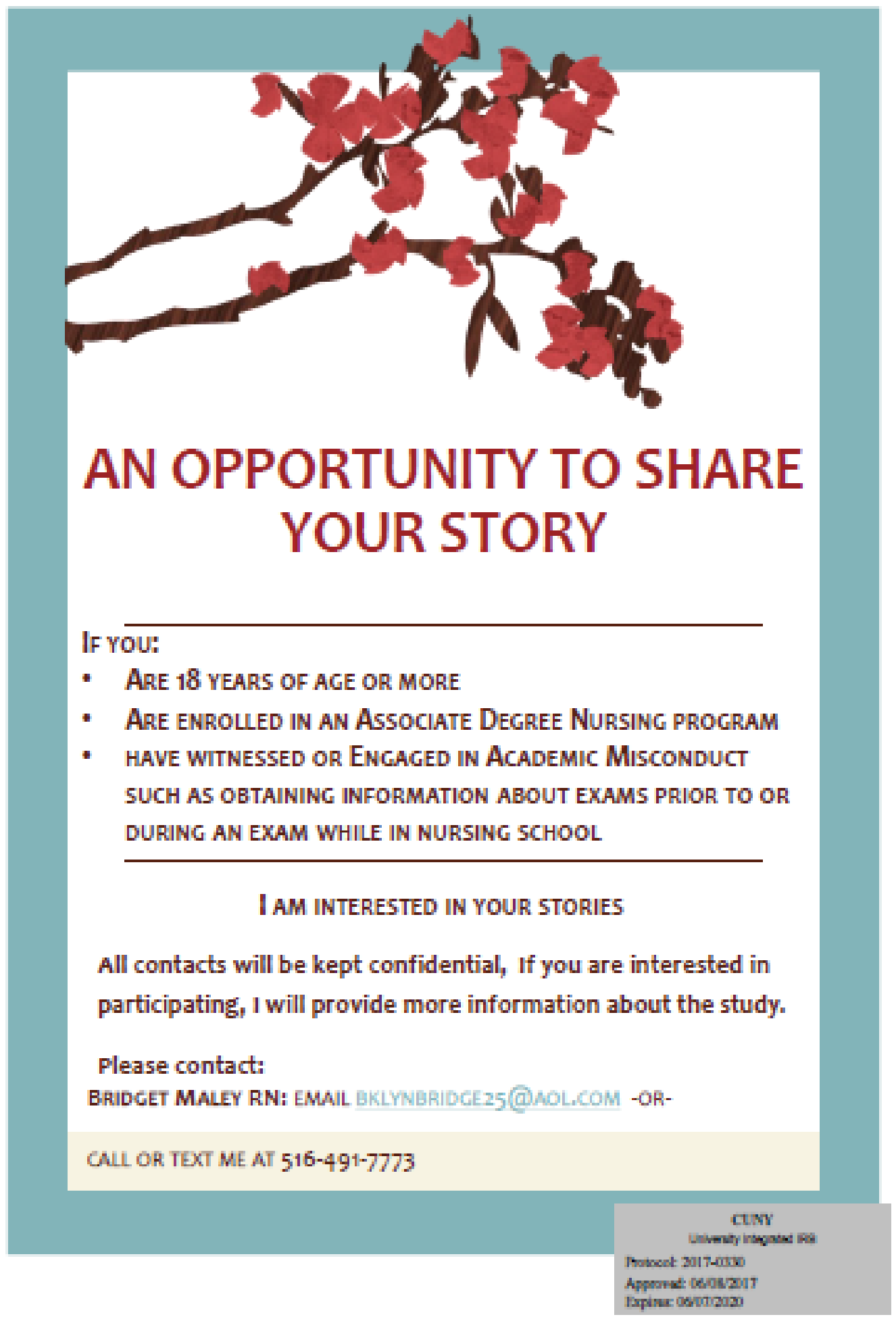




\author{
Appendix B \\ Informed Consent \\ THE CITY UNIVERSITY OF NEW YORK \\ CUNY Graduate Center \\ Nursing
}

\title{
ADDENDUM TO THE INFORMED CONSENT FORM NEW INFORMATION FOR CONTINUING RESEARCH PARTICIPANTS
}

Title of Research Study: A Narrative Inquiry of Associate Degree Nursing Students' Stories about their Experience of Academic Misconduct

Principal Investigator: $\quad$ Bridget Maley, RN, MS

CUNY Graduate Center

Faculty Advisor: $\quad$ Arlene T. Farren RN, PhD, AOCN, CTN-A, CNE

Associate Professor

College of Staten Island

2800 Victory Blvd. 5S-213

Staten Island, NY 10314

You are being asked to participate in this research study because you are a nursing student in an Associate Degree (AD) Nursing Program and have participated in or witnessed academic misconduct.

\section{Purpose:}

The purpose of this study is to gain a deeper understanding of AD nursing students' experiences with academic misconduct, which may include participation in or witnessing academic misconduct during their nursing education process and give voice to their storied experience.

Disclosure of Financial Interest: There are no financial conflicts of interest associated with the study PI, Advisor, or CUNY Colleges.

\section{Procedures:}

If you volunteer to participate in this research study, you will be asked to do the following: 
Agree to meet at a mutually agreed upon time and place.

Sign a consent form before beginning the interview.

Complete a short demographic form

Share your story of academic misconduct; which will be audio recorded so the story can be transcribed for review by the researcher.

You will be contacted by the researcher to create an appointment to meet with the researcher, or discuss your interview via the telephone.

At the completion of the data collection phase of the study, all participants who complete the study will receive a $\$ 10$ Gift Card

\section{Time Commitment:}

Participants may expect a time commitment of approximately 60-90 minutes.

\section{Potential Risks or Discomforts:}

There are no known potential risks that exceed day-to-day life experiences. It is possible to experience discomfort due to inner personal conflict when reflecting upon one's experiences with a potentially stressful experience. If personal conflict does occur, participants may discuss their feelings with the staff of their College Wellness and/or Counseling Center, which are services available to all enrolled students at their respective campuses without charge, or a personal or spiritual counselor at their own expense. Participants may withdraw from the study at any time.

\section{Potential Benefits:}

There are no direct benefits to participants, although the participants may experience growth, self-awareness, and find new meaning in their story. Participants completing the study will receive a $\$ 10$ gift card as a small token of appreciation for their time.

\section{Expected Benefit to Society:}

Participants' stories may enhance the understanding of witnessing or engaging in academic misconduct and provide insight to potential strategies for prevention of academic misconduct and support of students who either witness or engage in academic misconduct.

Costs: There is no cost associated with participation in this study except possibly the cost of transportation to the meeting place. 


\section{$\underline{\text { Alternatives to Participation: }}$}

As a student, your willingness to participate in this study, option to not participate, or your decision to withdraw from the research study will not affect your grades or academic standing at your College or in CUNY.

\section{Confidentiality:}

Every effort will be made to maintain confidentiality of any identifying information collected during the study. Disclosure of information will only occur with your permission or as required by law.

Participants will be given a pseudonym (code name) to protect your identity. The code book linking actual names and code names will be kept in a separate, locked file cabinet in the researcher's office for three years and then destroyed. Participants' actual names will not be used in any reports or publications about the research. The research team, authorized CUNY staff, and government agencies that oversee this type of research may have access to research data and records in order to monitor the research. Research records provided to authorized, non-CUNY individuals will not contain identifiable information about you. Publications and/or presentations that result from this study will not identify you by name.

\section{Participants' Rights:}

Your participation in this research study is voluntary. If you decide not to participate, there will be no penalty to you.

You can decide to withdraw your consent and stop participating in the research at any time, without any penalty.

\section{Questions, Comments or Concerns:}

If you have any questions, comments or concerns about the research, you can talk to the following researcher: Bridget Maley MS, RN 516-491-7773. If you have questions about your rights as a research participant, or you have comments or concerns that you would like to discuss with someone other than the researchers, please call the CUNY Research Compliance Administrator at 646-664-8918. Alternately, you can write to:

CUNY Office of the Vice Chancellor for Research

Attn: Research Compliance Administrator

205 East $42^{\text {nd }}$ Street

New York, NY 10017 


\section{Signature of Participant:}

If you agree to participate in this research study, please sign and date below. You will be given a copy of this consent form to keep.

Printed Name of Participant

Signature of Participant

Date

\section{Signature of Individual Obtaining Consent}

Printed Name of Individual Obtaining Consent

Date 


\section{Appendix C}

\section{Demographic Sheet}

Please place a check or fill in the appropriate information between the parentheses that best represents you.

A. How would you describe your gender?

\section{Male ( )}

Female ( )

Other: Please identify

B. Age: ( ) years

C. Which of the following programs are you currently enrolled
AD in Nursing ( )
BS in Nursing ( )
D. What semester of your program are you currently enrolled? 


\section{Appendix D \\ Interview Questions}

\section{Opening Question:}

Tell me your story of academic misconduct.

\section{Probing Questions:}

Tell me more about your experience with academic misconduct?

What kind of feelings emerged during this experience?

Were you changed by this experience?

What can nurse educators learn from Associate Degree nursing students' stories in order to promote academic integrity?

Has this experience with academic misconduct influenced your nursing education?

We are now at the end of the interview. Is there anything else you would like to add or discuss? 


\section{Appendix E}

Pastiche

The Row Not Taken Pastiche

by Bridget Maley of

The Road Not Taken

by Robert Frost

Two rows of seats from which to choose

And sorry that I cannot choose both

And being one student long I peruse

And looked down each for hidden clues

To where it is best for my growth

Then took the other as just as fair

And having perhaps the better view

Though as for me time was passing there

If I didn't choose quickly, I won't have a prayer

Which to choose I haven't a clue

And both that morning equally lay

Two rows of seats from which to choose

I must choose wisely on this day

Because knowing which one will make the play

I wouldn't want to be in my shoes

I shall be telling this with a sigh

Somewhere ages and ages hence;

Two rows of seats to choose, and I

I took the one less traveled by,

And that has made all the difference 